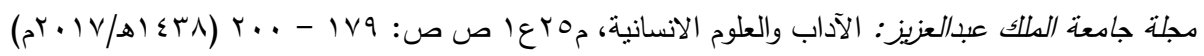

$$
\begin{aligned}
& \text { DOI:10.4197 / Art.25-8 }
\end{aligned}
$$

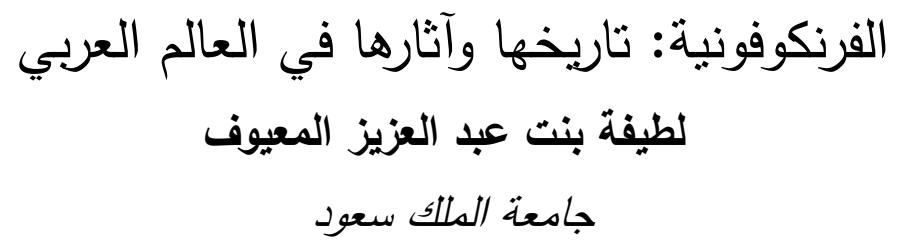

مستخلص تمنل الفرنكوفونية طريقا من طرائق التغريب والاستتباع التي نفذت إلى العالم العربي، وقد مرت بمراحل متعددة وأساليب مختلفة، بدأت بحماية الأقليات النصرانية في بلاد الثام (في القرن الثامن عشر أثناء الحكم العثماني)، ثم بالزحف الكولونيلي العسكري الدموي في المغرب العربي. سلبت الحركة الفرنكوفونية كل ما اسنطاعت من خيرات البلدان العربية، وعملت على طمس الهوية الإسلامية والعربية فيها، وبعد تحقق تحرير الأراضي العربية من قبضتها العسكرية؛ أبقت الفرنكوفونية ما يُيقي نواجدها واستمرارها. وقد خلفت الفرنكوفونية آثنارا جسيمة في البلاد العربية الواقعة تحت سيطرتها، من هذه الآثار ما هو على: اللغة العربية، والتعليم، والثقافة. الكلمات المفتاحية: الفرنكوفونية- الكولونيالية- المغرب العربي - اللغة العربية

ولأن سيطرة الفرنكوفونية على العالم العربي قديمة، ولها آثار ما تزال ظاهرة على المجتمعات العربية

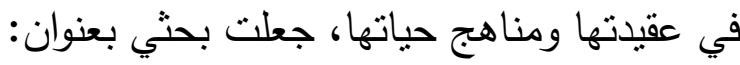
الفرنكوفونية: تاريخها وآثارها في العالم العربي. أهمية البحث

تثثير الفرنكوفونية في العالم العربي إثكالية ظاهرة ، وذلك من عدة أوجه:

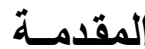

لقد واجه العالم العربي قديما أنماطا من

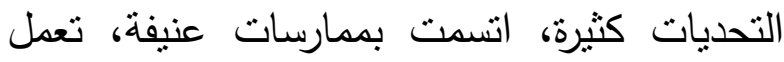

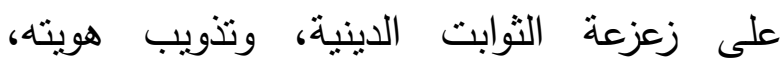
وبالتالي تهميش حضارته. ومن هذه الأه الأنماط الاحتلال الفرنكوفوني، الذي سعى لإبقاء نفوذه في

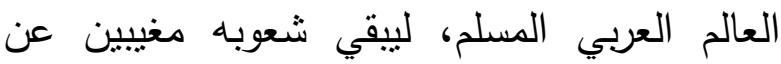
دورهم الحضاري، وخيرات بلادهم مستتزفة لغيرهم. 


\section{الداسات السابقة}

وهي الدراسات العربية العلمية والمتخصصة العصاتهات

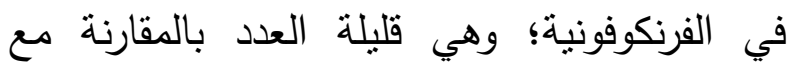

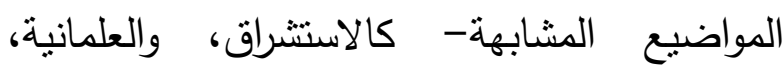

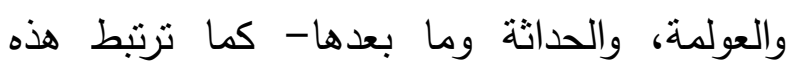
الدراسات بالقطر العربي (دون النظر للواقع العربي بشكل متكامل)*ثضاف إلى ذلك المواقع الإلكترونية

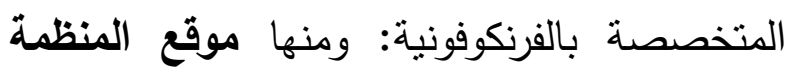

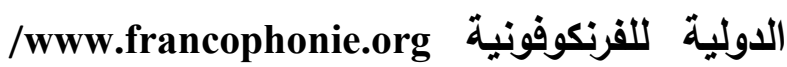
وموقع الوكالة الجامعية للفرنكوفونية مكئة / www.auf.org / وموقع الأنشطة الفرنكوفونية في الإنها مكتبة الإسكندرية www.bibalex.org

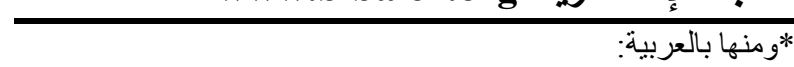
- تجليات العقل السياسي ومستقبل النظام العربي ، صلاح سالم ، (1991)

- ثمانون عاما من الحرب الفرنكوفونية ضد الإسلام واللغة العربية

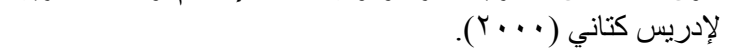

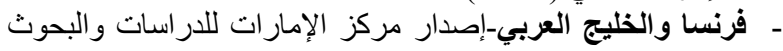

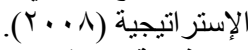

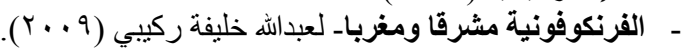

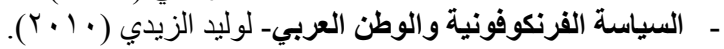

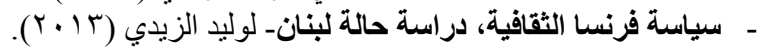

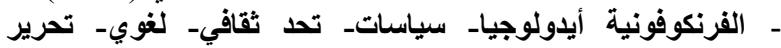

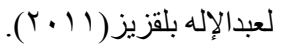

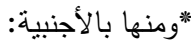

- Francophone Post-Colonial Cultures - Critical Essays - edited by Kamal Salhi 2003 by Lexington Books - USA

- Against the Post-Colonial Francophone Writers at the End of French Empire - Richard Serrano - 2005- by Lexington Books USA

- Between Languages and Cultures: Colonial and Post-Colonial Readings of Gabrielle Roy -Chapman Rosemary- 2009-McGillQueen'press

- Transnational French Studies Post-Colonialism and Literaturemonde - edited by Ales G. Hargreaves, Charles Fonsdick and David Murphy 2010 - Liverpool University press

- Adaptation: Studies in French and Francophone Culture - Neil Archer, Andreea Weisl-Shaw, 2012, Peter Lang.

$$
\text { مجال البحث }
$$

- أنها منظومة سياسية احتلالية تختلف عن

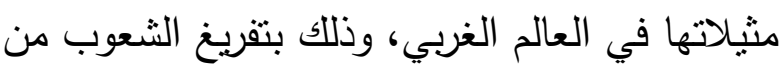
مقوماتها التي تميزها.

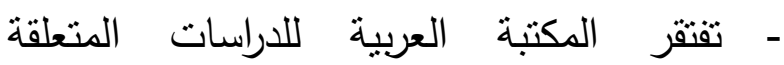

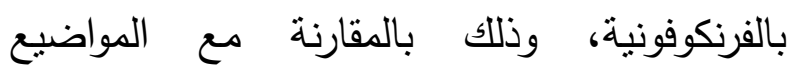
المشابهة. - تمثل القراءات العربية حول الفرنكوفونية- على القئل قلتها- وجهات نظر تختلف باختلاف القطر .

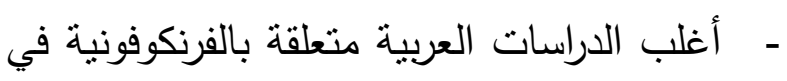

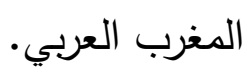

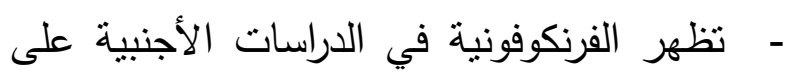
أنها نظرية فكرية، ظهرت ما بعد الاستعمار ، وهي

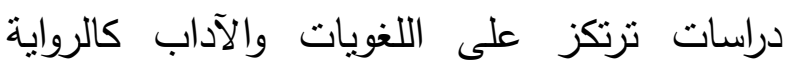
والثعر ، وأدب الحركة النسوية، دون التعرض لدوريات والدابل في الاحتلال وتفريس الثعوب بعد سلب الهوية. - السعي الحثيث في السياسة الفرنسية حاليا

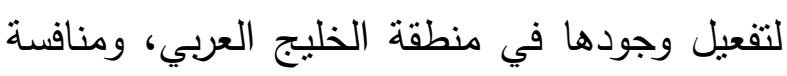

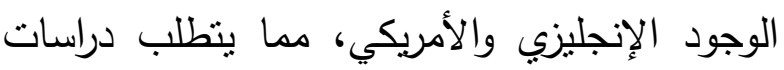

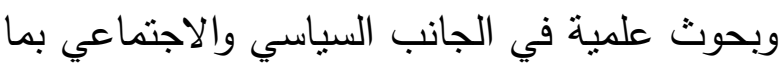
يخدم مصلحة المجتمع العربي.

$$
\text { أهداف البحث }
$$

- تحديد المبادئ الأساسية التي تحكم الفرنكوفونية وآثارها على العالم العربي.

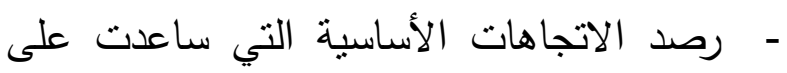
نشاط الفرنكوفونية في العالم العربي. - النظر في الكيفية التي مارست بها الفرنكوفونية نفوذها في العالم العربي. - - النظر في آثار الفرنكوفونية على العالم العربي. 
أعطاها الصيغة اللغوية حسب الجغرافيا التي تتتشر فيها اللغة الفرنسية (ولا سيما فرنسا، وشمال أفريقيا). وبشكل أكثز تحديدا عرف ربكلوس مفهوم الفرنكوفونية بأنها "مجموعة السكان الذين يتكلمون

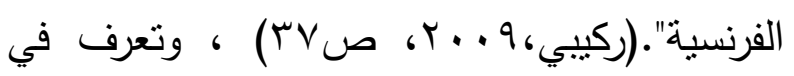
الوقت الحالي بأنها" مجموعة الدول و الأقاليم الناطقة بالفرنسية" (فورسدك، ع ا ـ Forsdick، (F). يرى الباحثون العرب أن هقيقة الفرنكوفونية هي "أيديولوجيا تعيد إنتاج علاقات التبعية، مستثمرة الموروث اللغوي الاستعماري لأغراض سياسية واقتصادية". (بلقزيز 9VV 9 ( كص 7 7). ويرى باحثُن آخرون بأن هذا المصطلح "لا" الا يركز على الجانب المادي كما هو الحال في الاحتلال البريطاني، بل يسعى أساساً إلى الهجوم

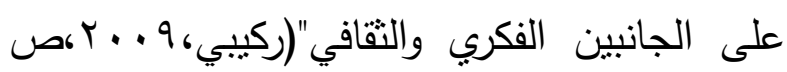
. (1)

في حين يرى بعض الباحثين الغربيين أن " مصطلح الفرنكوفونية في حد ذاته مشكل في استخداماته السياسية، واللغوية، والثقافية، والتي أعطت معنى غير واضح من قبل أشخاص مختلفين" (فورسدك، ـ ا • Forsdick ، F). ثالثا: النشأة ويداية الظهور: الفرنكوفونية في هيئتها ومضمونها نسيج يختلف عن القيادات الفكرية والسياسية التي واجهت العالم العربي، إذ تختص الفرنكوفونية بفرنسا خاصة، في حين تتضوي كل القيادات الغربية ومن
إن دراسة الفرنكوفونية في العالم العربي لن تنتاول كل قطر بصورة منفردة ومنعزلة؛ وإنما بتقسيم نفوذ الفرنكوفونية، وآليات النفوذ، وآثاره من خلا نظرة شمولية تعالج أهم القضايا المتواجدة مع جزئيات التبيان في المشرق والمغرب العرب. وتحري تأثير الفرنكوفونية في العالم العربي في صورته الواقعية الحقيقية من خلال طروحات المؤلفين المختصين.

منهج البحث: المنهج الاستقرائي لسياسة الفرنكوفونية في العالم العربي، وطرق نفوذها فيه، وآثارها عليه. خطة البحث: اشتملت خطة البحث على: مقدمة، وثلاثنة مباحث، وخاتمة. المبحث الأول: مفهوم الفرنكوفونية وتاريخها: أولا: التعريف: هي كلمة فرنسية يعرفها معجم (Lafranchopnie) لاروس الفرنسي "بأنها التجمع الذي يضم الشعوب الناطقة باللغة الفرنسية" (دبوبوا،ه9 9 (1). ويقابلها في اللغة الانجليزية (Francophone) وتعني "استخدام اللغة الفرنسية كاللغة الأم، أو اللغة الأولى، أو اللغة الرئيسية" (البعلبكي، • 199 ) ) و( Longman Dictionary of contemporary English ,2006).

ثانيا: مفهوم الفرنكوفونية: يعد مصطلح الفرنكوفونية مصطلحا معاصراً، إذ أطلق هذا اللفظ من قبل الجغرافي الفرنسي

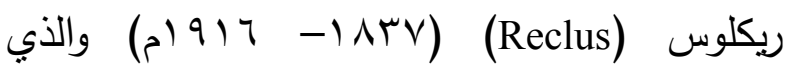


رعايا فرنسا امتيازات تجارة وإقامة، وهي امنبازات منحها

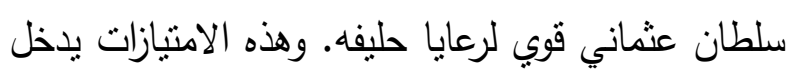
فيها كل قطر يقع تحت سلطان الدول العثمانية (ومنها

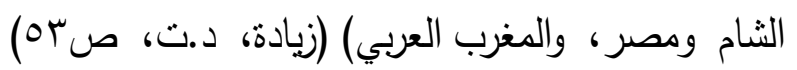

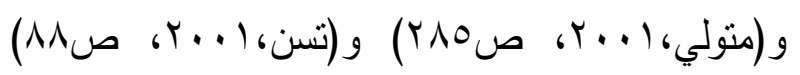

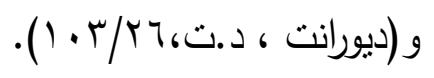

وفي الوقت الحاضر، لا تزال تحظى الفرنكوفونية باهنمام السياسية الفرنسية، فالثؤون لران الفرنكوفونية "تديرها بشكل مباشر ، ومتخصص في

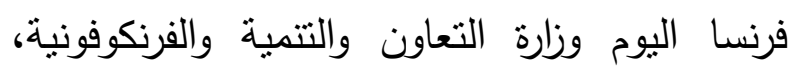
ولعل تخصيص وزارة معنية بالثؤون الفرنكوفونية في فرنسا يعطي إثنارة واضحة على أهمية الفرنكوفونية في أجندة الحكومة الفرنسية، ومدى بـى الطموح السياسي والآمال التي تضعها فرنسا في فئني

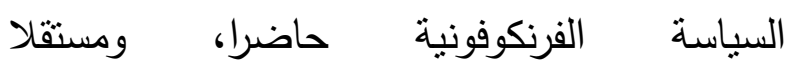

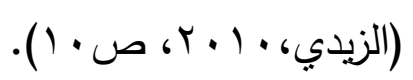

المبحث الثاني: آليات النفوذ الفرنكوفوني في العالم

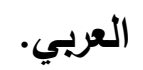
أولا الأقليات النصرانية :

كان وجود أقليات نصرانية في العالم العربي : لهي

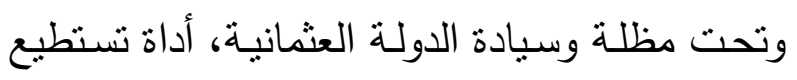
من خلالها الفرنكوفونية وغيرها من النظم السياسية

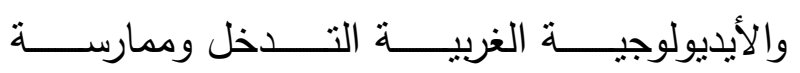

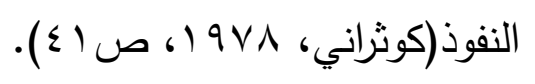

ضمنها فرنسا تحت ما سُميّ بالاستشراق؛ والذي يهدف إلى دراسة الثعوب الأخرى واحتلالها،

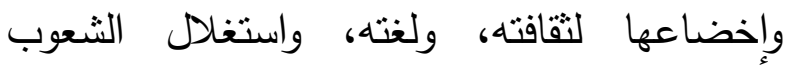

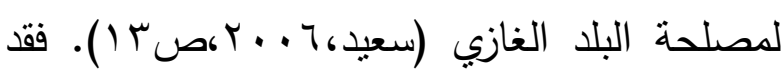
ارتبط الاحتلال الفرنسي بتاريخ غزوه اللغوي للدول التي امتد نفوذه إليها، وقد بلغ نفوذ اللغة الفرنسية قمته في القرن الثامن عشر؛ حيث حلت اللغة الفرنسية في أوربا محل اللغة اللاتينية المتراجعة،

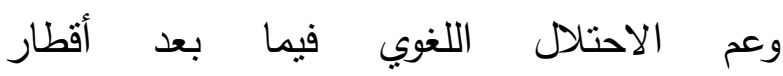

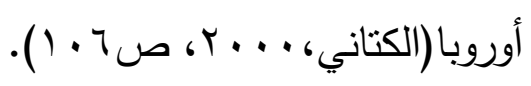

وفي العالم العربي والإسلامي، يذهب بعض

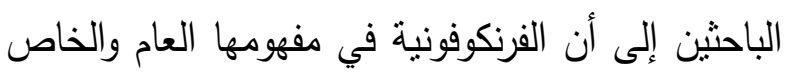
ماهي إلا "تنار حديث النشأة، وليس لها جذور ناريخية عميقة، إذ انطلقت في أعمالها بعد إحياء فكرتها

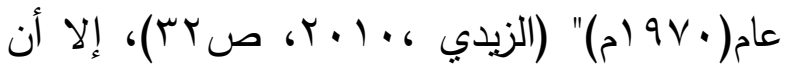
التاريخ يشهد بوجود آثار للفرنكوفونية ونشاطها في العالم العربي والإسلامي على حد سواء، وفق أهدافها ومساعيها، وذللك منذ أول معاهدة عثمانية

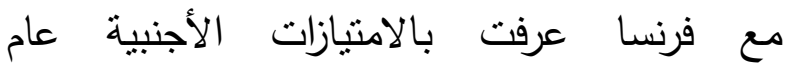

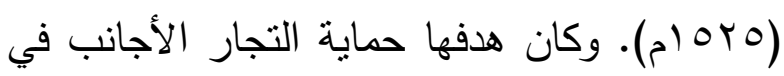

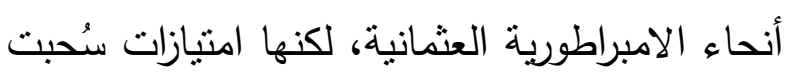

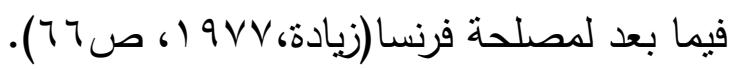
وفي أوائل القرن الساد عشر، عقد سليمان

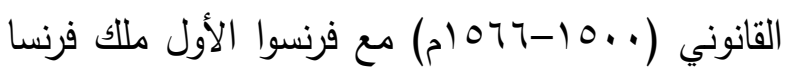

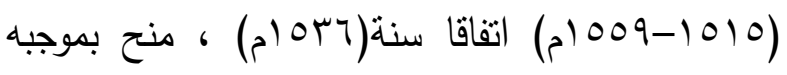


وقد استطاعت فرنسـا من خـلال هذه الثرائح

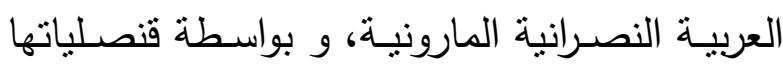
في دمشق وبيروت أن توجد أنباعا لها وتجعل منهم

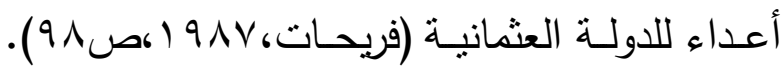

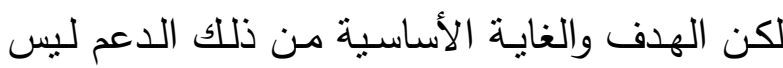

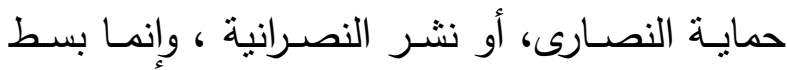
النفوذ والسيادة والسيطرة، فقد ظهر ذلك جليا عندما تحققت فرنسا من أن الأتراك القوميين أقوى من أن فئن

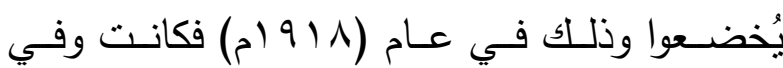
الوقت الذي تقاتـل الكمـاليين الأترالك في الجنـوب التواب الثـرقي لتركيـا، تتفـاوض معهم بهدوء وكتمـان،

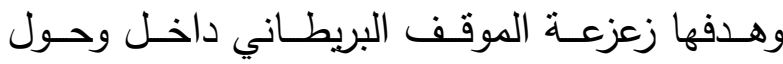
أسطنبول بـل كانت توفر للأتراك السـلاح والذخيرة

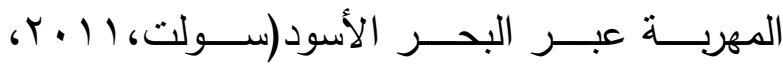

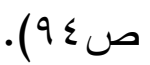

\section{ثانيا: القومية العربية}

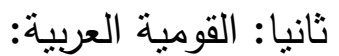

اعتبر العرب الدولـة العثمانيـة دولـة إسـلامية،

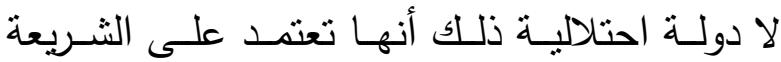
الإسلامية في نظامها وتعتبر دار الإسلام. إلا أنـه وبسـبب اضـطهاد الاتحـاديين التـرك للعرب، وذلك بعد مطالبة العرب بحقوقهم السياسية والمشـاركة الفعليـة في إدارة شـؤون الدولــة، وجعـل

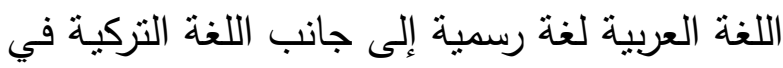
البرلمـان العثمـاني، وأن تكـون رسـية في الولايـات

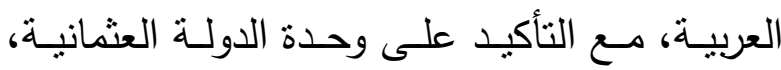

إذ قام رجال دين، وسياسيون أوروبيون بإقامة مطالب باطلة لتكون منفذا للتنخل السياسي والديني. ومـن ذلـك المطالبـة بحقوق مـا يسـونه "الأقليـات النصرانية المعرضة لثرور الحكومات المتعاقبة في

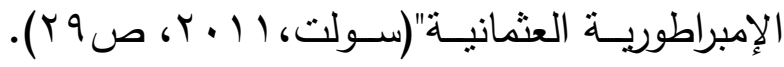

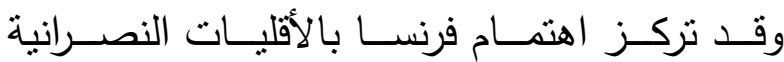
المنواجدة في المشـرق العربي (بـلاد الثـام) فقامت فرنسا بالمطالبة بحقوق "الملل المرتبطة بكنيسة روما وذلـك بجعلهـا أقليـات دينيـة دخلـت فـي التتظيـر الكولونيالي، كمسألة مشروعة تبرر عمليـة التدخل

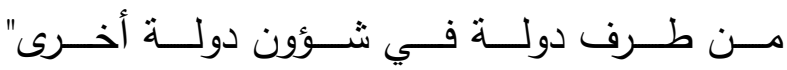

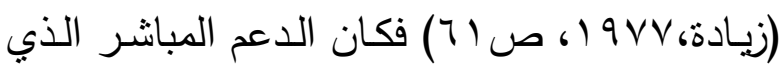

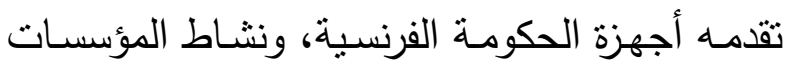
الخاصة من خلال انتتـار المدارس في جبل لبنان

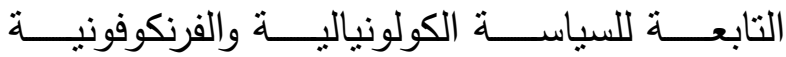
والإرساليات، والمؤسسات الثقافية تحت شعار حماية فرنسا للكاثوليك؛ إذ شهدت أروقة الخارجية الفرنسية ولادة نظريـة حمايـة فرنسـا للاتينيـين، وللنصــارى المشـرقيين التــابعين للبابويــة مـن ذوي الجنسـية

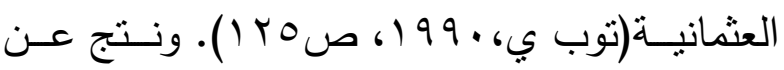

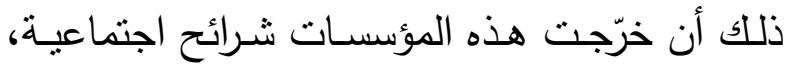

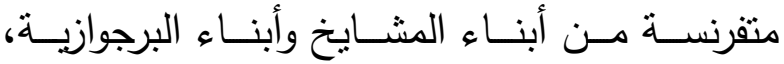
المارونية، الصـاعدة، وقد شكلت هذه الثرائح عبر

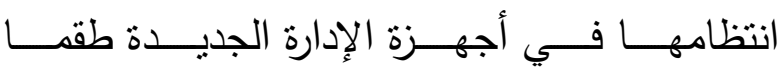

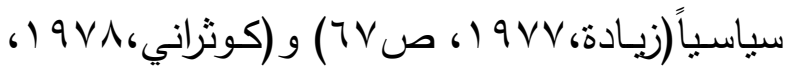
ص (ب)، له منظوره الخاص في الحياة. 
ذلك أنها كانت تعتقد أن وجود الثورة قد يحول دون استقرارها في سوريا. كما كانت تخثى من تأثنر هذه

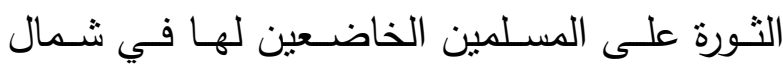
أفريقيا، فتقوي من حركاتهم الاستقلالية وتطلعاتهم

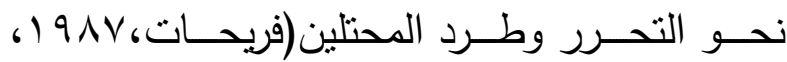
ص هץ). إلا أنها مـا لبثت وأصدرت التأييد للثورة العربية ضد الدولة العثمانية؛ وذلك من خلال بيان ورد فيه: "أن الثورة العربيـة ضد الاحتلال العثمـاني كانت إيجابية إلى حد ما للمصالح الفرنسية... فهي تحـد مـن النفـوذ التركي فـي المنــاطق (فلسـطين

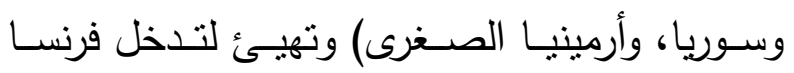

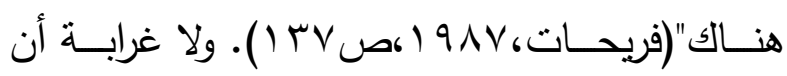

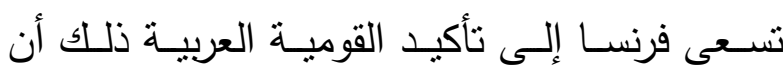
"مجالهـا محصـور وضـيق بالمقارنــة مـع القوميـة

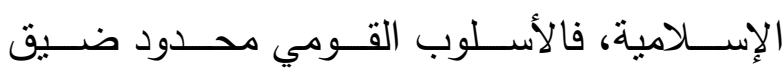
المسـاحة، لأنه يحصر نفسـه في فكرة واحدة ، فهو

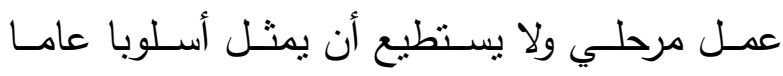

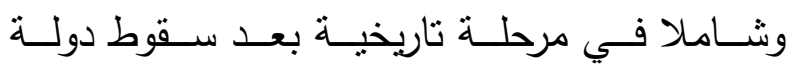
عملاقة" (الجندي، عـ 91 (،ص • بr). ثالثا: الحملات العسكرية الكولونيالية. يمثل الغزو العسكري الصورة الواضحة للنوايا الفرنسية غير المعلنة لمحاولة التذخل قديما وحديثاً. وقد كان النفوذ الفرنسي واضـحاً في التغلغل الاقتصـادي في جبـل السـتين بلبنـان وخاصـة في الأوساط المارونيـة، (إذ يتكون المجتمع اللبناني من

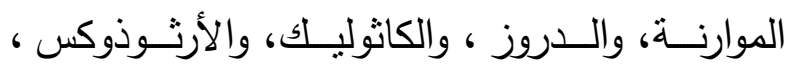

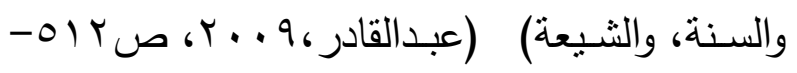
. (Ort
وعــدم الــدعوة للانفصــال عنها(ســولت، I1 ـ بـ، صع 9). هذه المطالب جوبهت بالتعسف والبطش

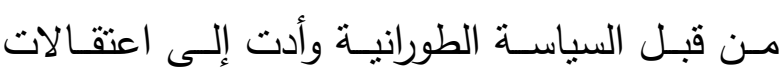
وإعدامات طالت العرب مـن المسـلمين والنصـارى، ومسن ثم اتسـعت هذه السياسـة لتتــل جميـع رجـال الحركة العربيـة بالإعدام، ونفي الأسـر العربيـة إلى هـي الأناضول (فريحات، 9 (9 ( ، ص 7 7). بالتـالي قامــت حركــة التحـرر مـن الحكـم

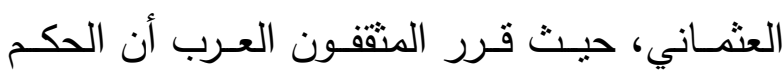
العثماني رمى الثعوب العربية في مرحلة الانحطاط

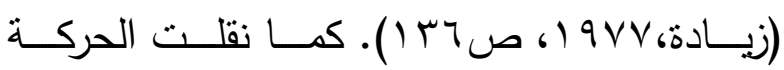
نشـاطها إلى خارج الدولة العثمانيـة، وذلك لتضـمن التهن

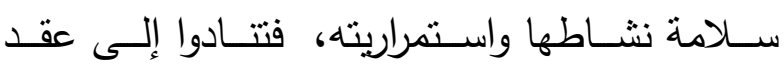
مؤتمراتهم في باريس. وكان أول هذه المؤتمرات في

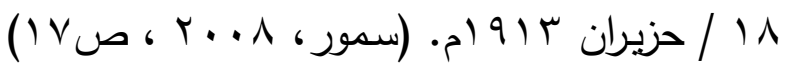

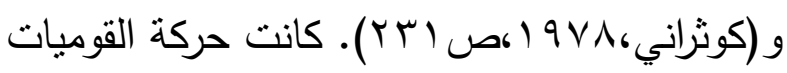
في الدولة العثمانية بالغة الخطورة؛ لأنها استُخدِمت

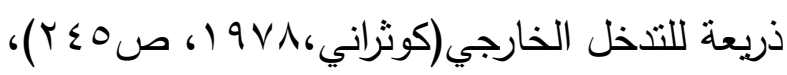

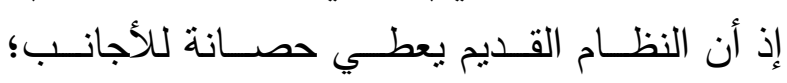

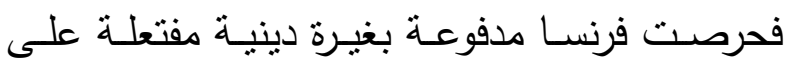

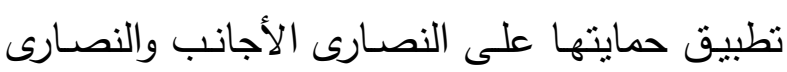
العـرب. لـا سـعت للاسـتفادة مـن النزاعـات الدينيـة والانتفاضــات القوميـة فـي جعلهـا ذربعـة للتـدخل

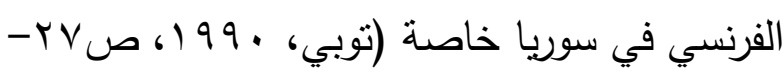

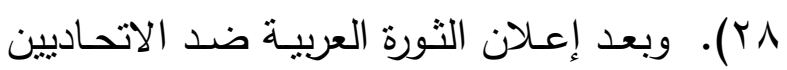

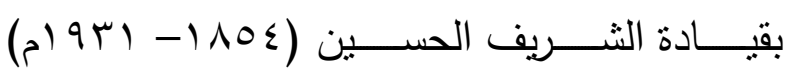

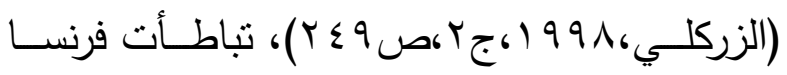
على عكس بريطانيا وروسيا، في تأييد ثورة العرب، 


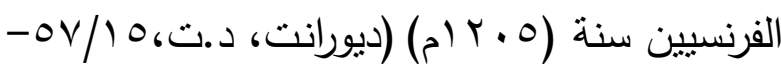
.01

كما كان للفلاسفة دور في بث الفكرة إذ قام

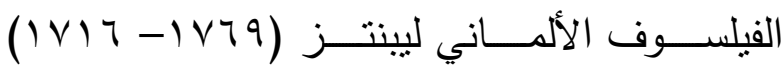
(رايت، • ( • Y، ص r T ( ) بإقناع الملك لويس الرابع

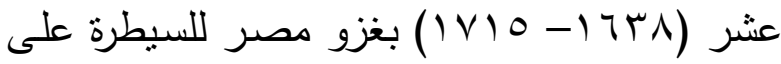
منافـذ نشـاط الهولنـديين في الهند، إلا أن الملـك الفرنسي رفض ذلك لمـا يترتب عليـه مـن فقدان

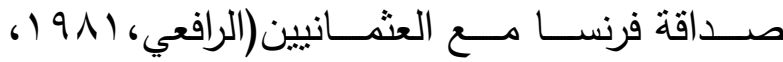

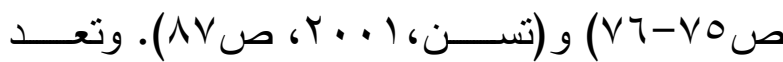
الحملة الفرنسية على مصر في ب/ يوليو (V91 ام)

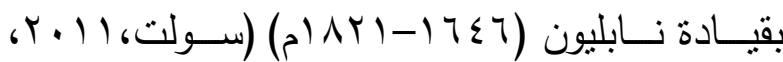

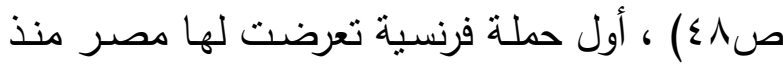

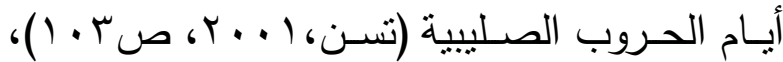
وقد كانت أطماع نابليون في دخول واحتلال مصر ليتخذ منها قاعدة عسكرية يصل منهـا إلى أمسلاك بريطانيا في الهند، وتحويل البحر الأبيض المنوسط

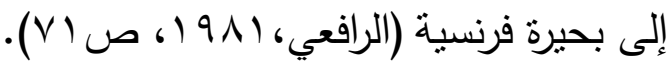

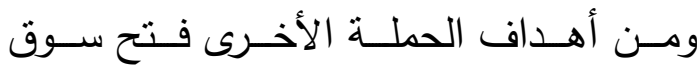

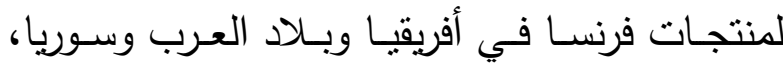

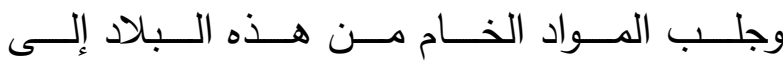

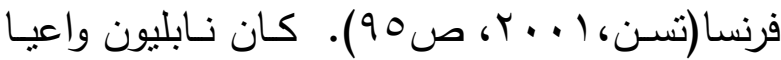
لأهميـة الـروابط التاريخيـة والدينيـة بين المصـريين

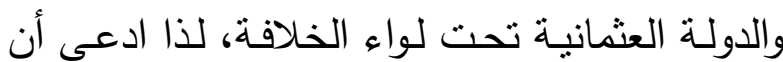

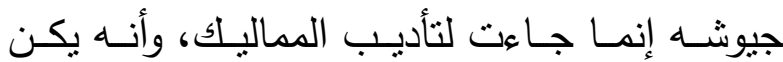

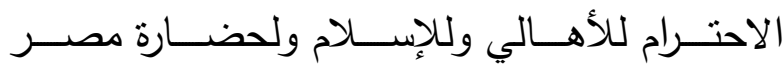

وبشكل عـام كانت الدول الأوروبيـة لا تتفك عـن التــخل في شـؤون الدولــة العثمانيـة بطــق

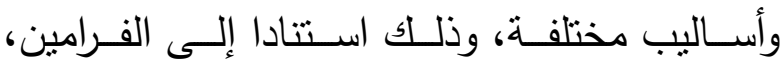
والمعاهدات التي أصدرها أو أبرمها سلاطين الدولة ودئة

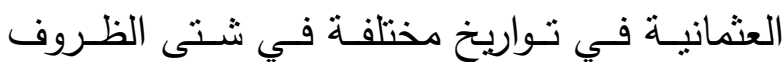

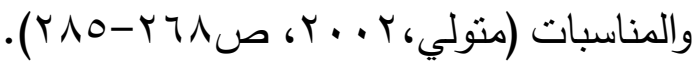
تمثل الحملة الفرنسية على العالم العربي دورة

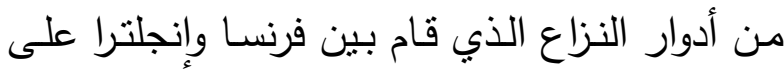

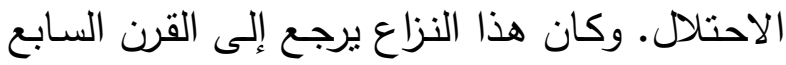

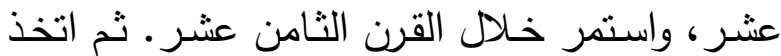
صورا جديدة بعد الانقلاب الكبير المعروف بالثورة الفرنسية، وسقوط الملكيـة وإعـلان الجمهوريـة عـام (Y Y (م)، وما تنا ذللك من رفض الدول الأوروبية

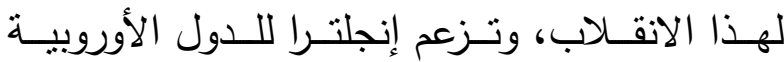
لمواجهة زحف الجيوش الفرنسية نحو أوروبا. وقد حققت فرنسـا انتصـارات بـاحتلال أجزاء مـن القارة الأوروبية، إلا أن بريطانبا بقيت بعيدا عن الزحف،

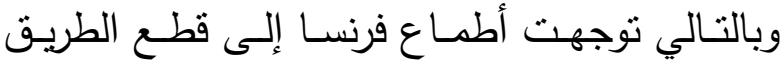
البحري في البحر الأبيض عن بـاقي المستعمرات

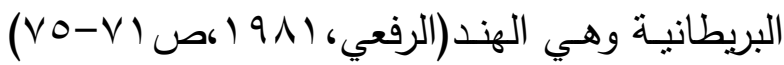

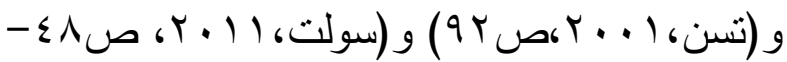

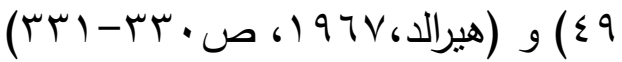
كان احتلال مصر فكرة مطروحة في السياسة الفرنسية منـذ القرن الثالث عشـر، إذ جهزت حملـة باسـم الــرب الصـليبية السـابعة انتهـت بهزيمـة 


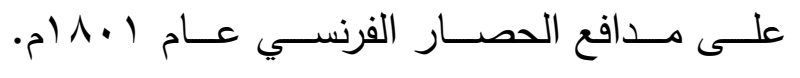

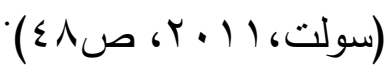
ولم يكن الوجود البريطـاني عارضـا "إذ كان التحالف الفرنسي الماروني مؤديا إلى بروز تحالف

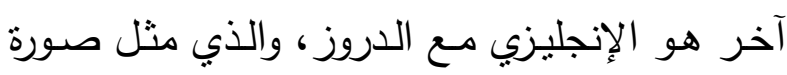

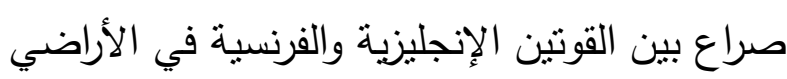

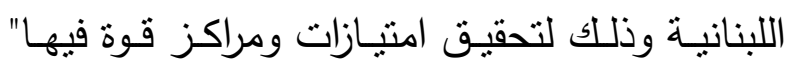

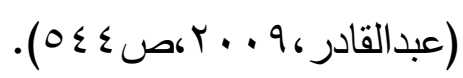

انتهت الحمـلات الفرنسية على مصر والثـام وتحدد وضـع مصر السياسي في صلح إمبان الذي

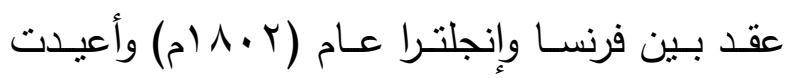

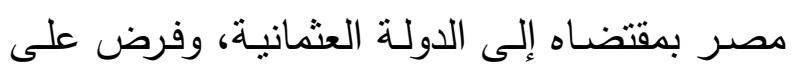

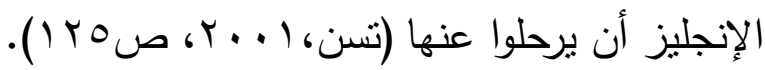

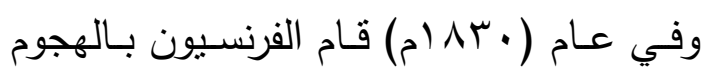
العسكري الثاني على أراضـي المسلمين في شمال أفريقيا إذ وصل الأسطول في با با يونيو ، و خـلال

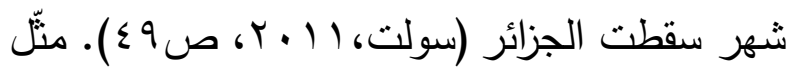

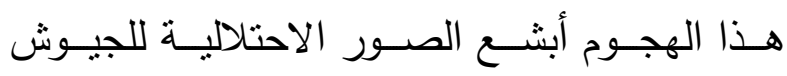

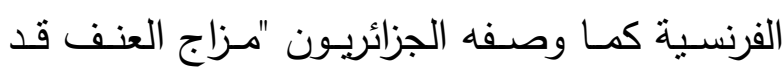
عرفناه نحن الجزائريين في أعنف صسورة وأثـرس مظاهره، فهو لا يكتفي بامتصاص الدم والعرق، بل

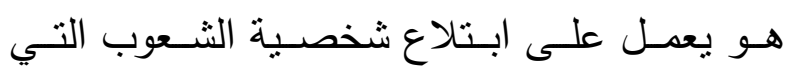

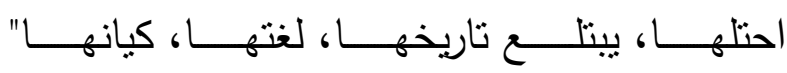

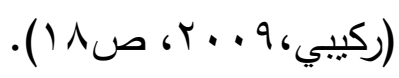

يعد هذا الاحتلال "الأوسـع عمقا للاستعمار الفرنسـي في بلـدان المغـرب العربـي، وقد تهيـأت
العظيمـة، كمـا ســعى نــابليون لإقتـاعـاع الســلطان العثماني أن الحملة على مصر ليس عمـلا عدائيا

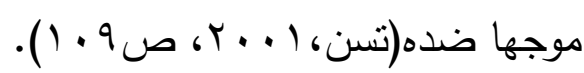
كـان دخـول الفرنسيين مصـر بمثابــة انفجـار

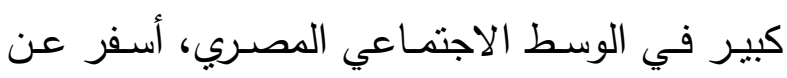

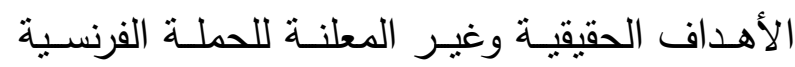

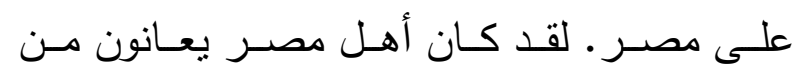

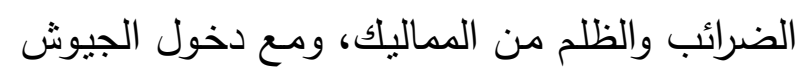
الفرنسية اجتمع على أهل مصر مصيبتان، وخاصة في جباية الضرائب من المماليك والفرنسيين في آنٍ آندي واحد، وتزامن هذا الظلم مـع فسـاد الجند الفرنسيين واستهتارهم بالثعب، وقد" أدى ذلك إلى ثورة أهالي التي

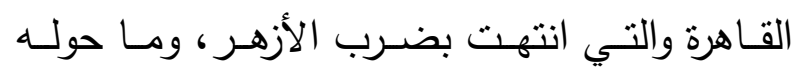

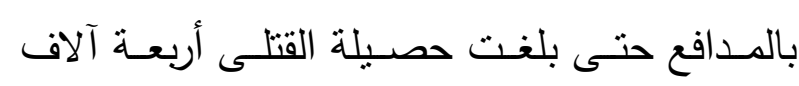
قتيل، كما دخلت الخيول الفرنسية الأزهر ، وعاثوا

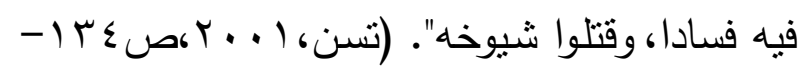
. (1)

أدركت بريطانيـا خطورة نفوذ الفرنسيين في

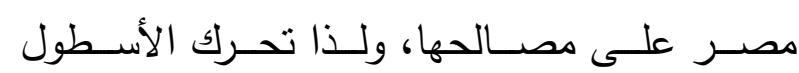

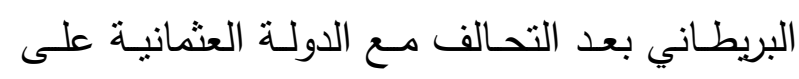

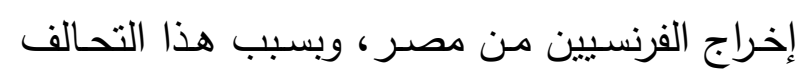

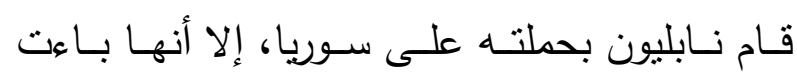
بالفتشل وذلك لانتشار مرض الطاعون بين جنوده،

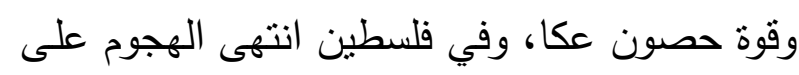
عكا بانهيار الجيش الفرنسي واستنيلاء البريطانيين 


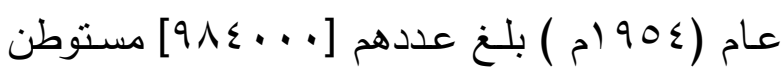

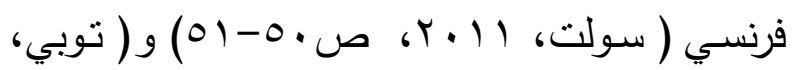

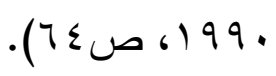

\section{رابعا: فرنسة النخب العربية :}

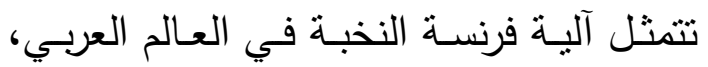
بتكوين طبقة عليا من أهالي البلا الأصليين مطبوعة

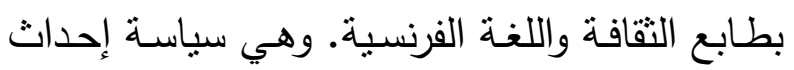
بنيات اجتماعية جديدة في الدول العربية، تقوم هذه وفئه

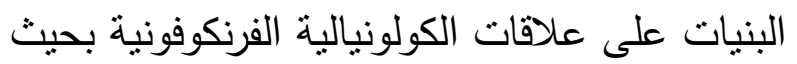
ييقي المحتل الضعيف تابعا للمحتل المستعمر بعد

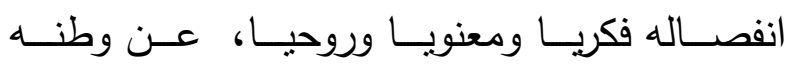

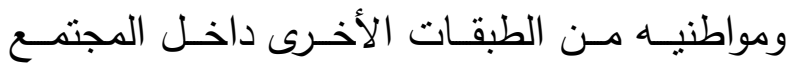

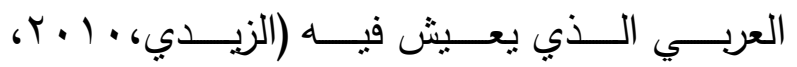

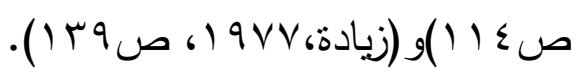
كانت تلك السياسة قديمة، ظهرت نتائجها، و أعطت ثمارهـا خاصـة في مجـال التعليم، إذ يعتبر

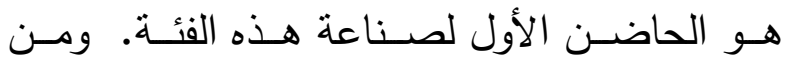
الأمتلة على ذلك المعهد السلطاني العثماني (غالاتا

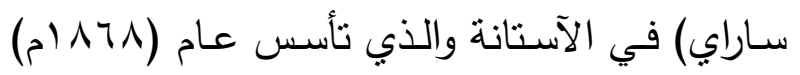
بدعم مباشـر مـن الحكومـة الفرنسية، وطـلاب هذا

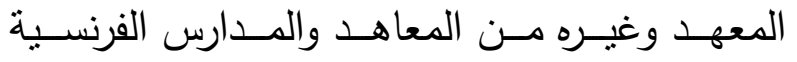
المنتشرة في السلطنة العثمانية؛ هم من أبناء رجال

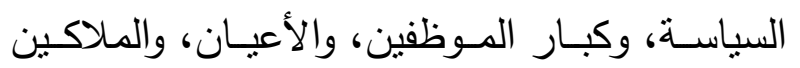

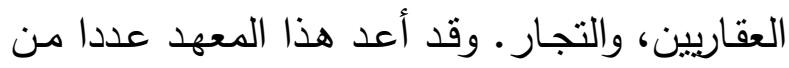
رجـال السياســة الـذين تولــوا إدارة السـلطنة، ومـن

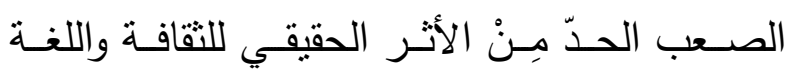

الظـروف المناسـبة لتعميـق النزعـة الانفصـالية في

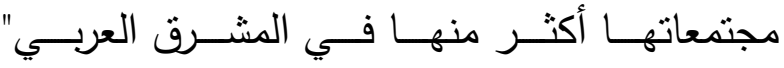
(الزيدي، • ( • r، صم ب (). لقد كانت الحملة الفرنسية في المغرب العربي لفي لفي مختلفة عنها في المشرق، فقد "كانت تتطلاب أكثر من ذلك بكثير : إنجاز جراحة ثقافية ولغوية تسنتبع

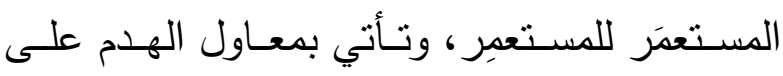
استقله شخصيته وكيانه، فتدفع إلى اقتداء الغالب

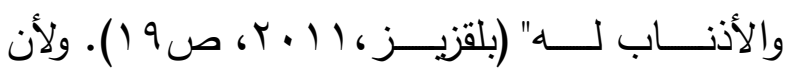

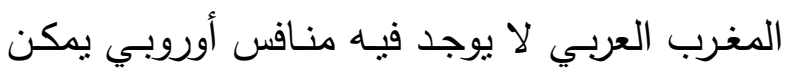

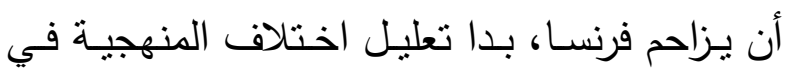

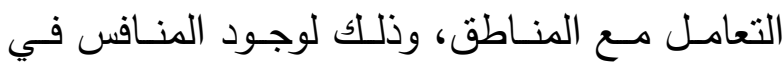

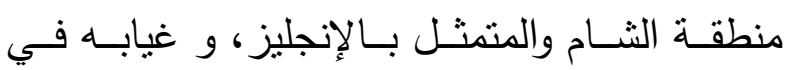

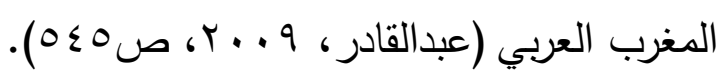
كان الهجـوم الفرنسـي على المغرب العربـي

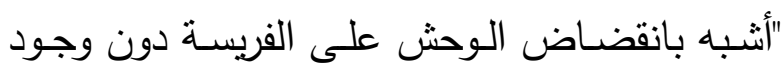

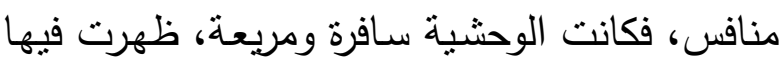
أبشع الصور الاحتلالية. فمع سفلك الدماء، وتدمير

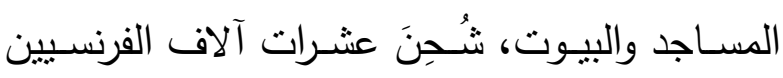
من الرجال والنساء في العقد التالي ليحولوا الجزائر

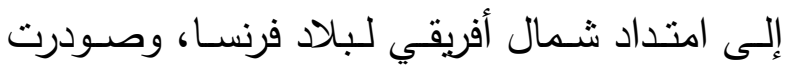

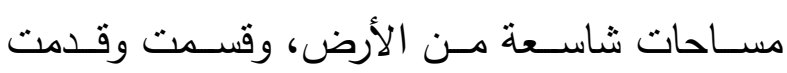

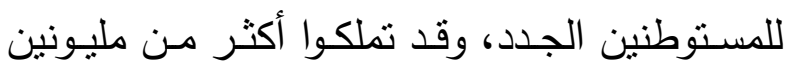

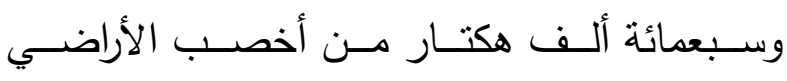

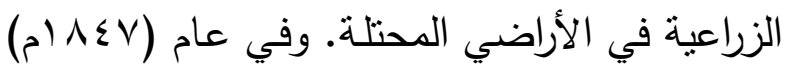

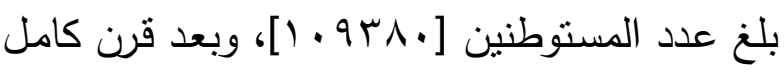




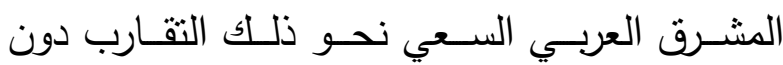

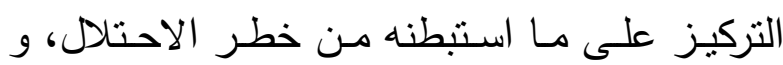

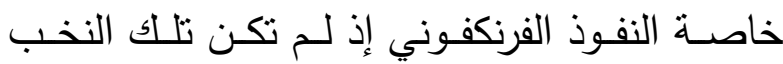

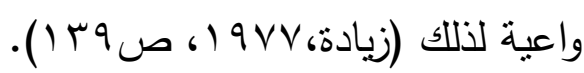
أما في مصر فقد كان الاستهداف مركزا على (ريادة

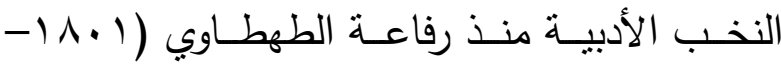
( I N الذي اعتبر الفرنسيين أقرب إلى المصريين من الأتراك. كما كان نشر الرواية والمسرحية وغيرها

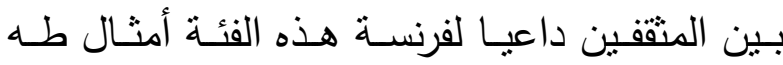

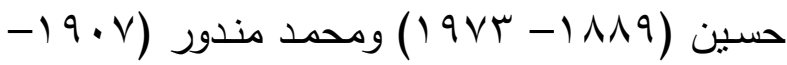

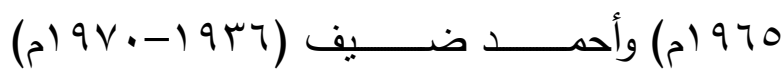

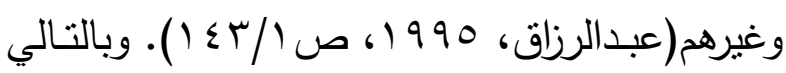
كـان نشـاط النخب المتفرنسـة في المشـرق العربـي ومصر محدودًا جداً، ويكاد أن يكون أثرها غير ذي لئن

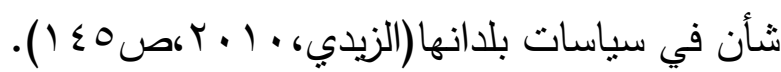

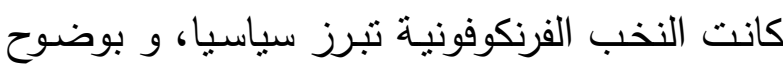
في مجتمعـات المغـرب العربس، فقي تـونس منّل

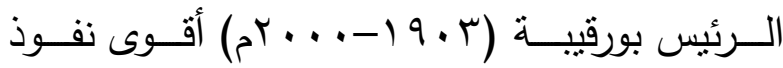

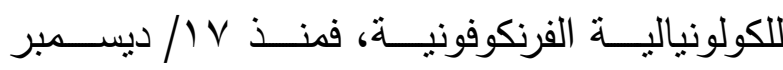
(900 (م) أيد الرئيس انضـمام تونس إلى الاتحساد

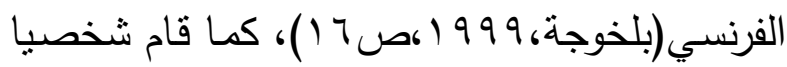

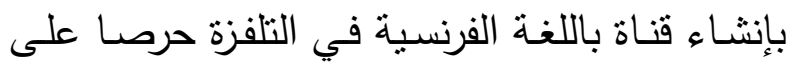

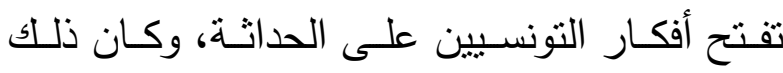

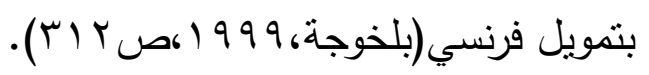

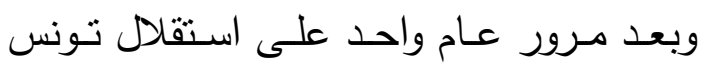

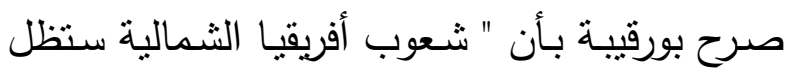

الفرنسية فيها، ومـا بثيـره مـن تعـاطف تلقائي هـع الفرنسيين فتظهر آثاره اللاحقة ويؤتي ثماره السياسية بعد حين(توبي، • 99 (، ص. • ب (1)).

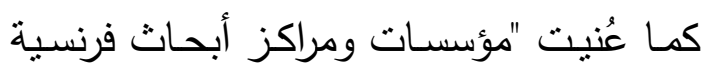

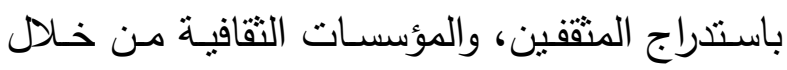

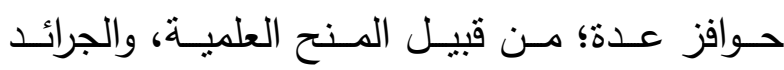

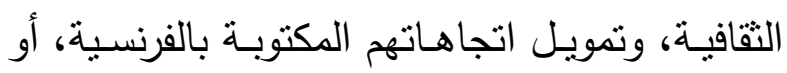
تمويل ندوات نقافيـة تتوافق مـع أهداف المؤسسـات

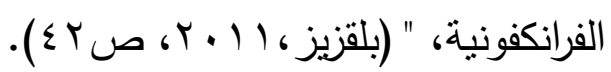

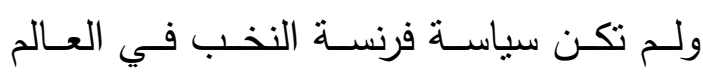

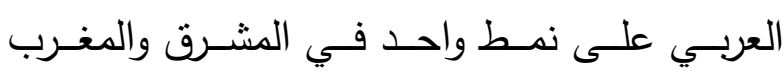
العربيين، فقد كانـت المعونـات تقدم إلى المدارس واس والمؤسسات الاجتماعية في المشرق العربي وتتراوح

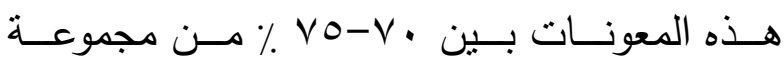
المسـاعدات الفرنسية. تقدم هذه المسـاعدات الماليـة للمؤسسات التربوية تحت ستار دعم المصالح العليا

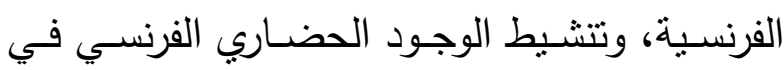
الثرق، حيث احتلت سوريا موقعا خاصـا في دائرة اهتمام الخارجية الفرنسية لتدعيم الركائز المحلية كي

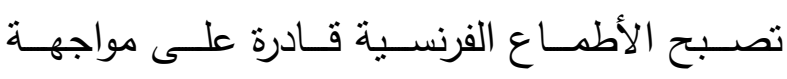

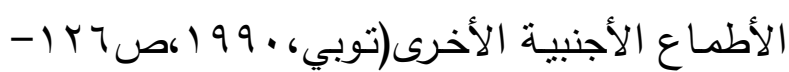
.$(1) 9$ إلا أن الأمــر الــذي ســـاعد علــى النفــوذ الفرنكفوني في المشرق، هو ذللك التقارب والارتباط الاقتصادي والثقافي القديم الذي صنعه الغرب بينه وبين الدول العربية، فجعل هدف النخب العربية في 
وإذا كانت التربيـة باعتبارهـا وظيفـة اجتماعيـة

(ذات أهمية كبيرة في تطوير المجتمع)، فإنها يجب أن تتميـز بالقصـــ الـذي يوجـه حركتهـا ويكسـبها

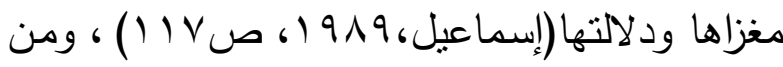
هذا المنطلق ليس من الغريب ورود العبارة البالغة الدلالـة التي جـاءت في مجلـة الرسـالة الاستعمارية الفرنسية لعام (9.9 (م) "المدرسة هي الأداة الحديثة

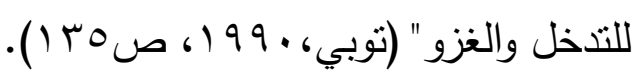

مكمن الخطر في هذا النمط من التعليم حين تشرف عليه الدولة المحتلة، و المؤسسات التبشيرية التعليمية، وجيش من المستشرقين الذين اتخذوا من لتنهات العلوم، والكتب، والموسوعات، والندوات، والدوريات

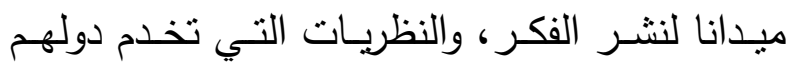

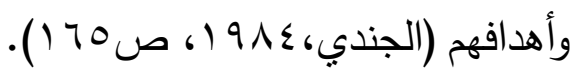

لـذا يشـــل التعلـيم العامـل الأساسـي لنشـر

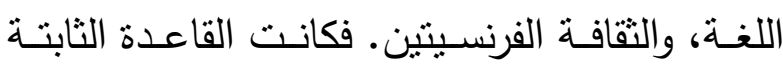
والصلبة التي مهدت للتعليم العالي وابتعاث النخب

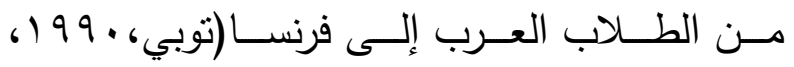

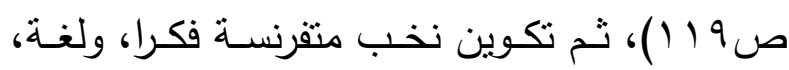
بعيدة عن دينها الإسلامي، و قيم حضارتها لتصبح

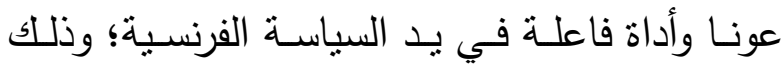
لاختراق المجتمع العربي والتحكم في إعادة تكوينه

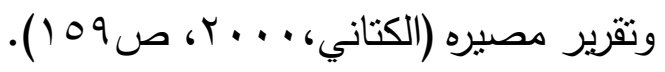

وجـدت السياسـة الفرنسـية في التعليم المنفذ

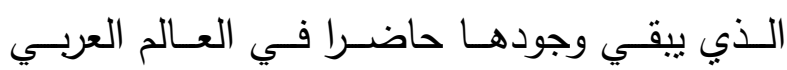

مرتبطــة بفرنسـا ثقافيـا وجغرافيـا واقتصـاديا ... إذا

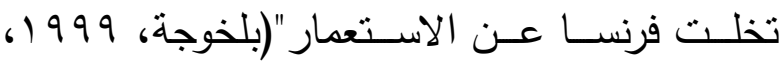
صץ § )، ويعـد بورقيبـة مـن المؤسسـين والبـاعثين

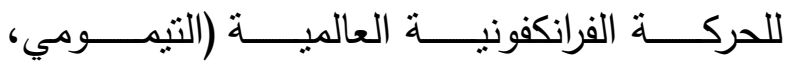
.$\left.\left(Y+T_{6}\right)\right)$.

وفي المغـرب كانــت الفرنسـة شـاملة جميـع الجوانب السياسية والاقتصادية والثقافية، إذ تضافرت هذه الجوانب على سلخ الهوية العربية تماما، وسعت

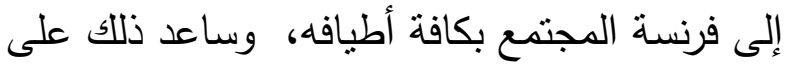
إنشـاء جيل يستطيع أن يحقق المهمـات التي يـراد

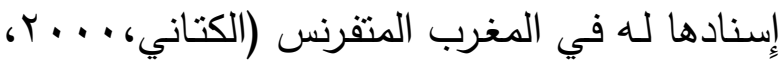
ص. • (1)، فبعـد" اسـتقلال المغـرب السياسـي عـام

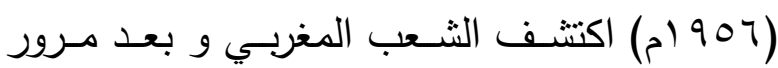

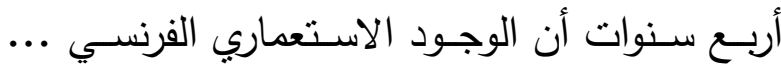

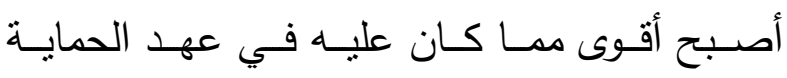

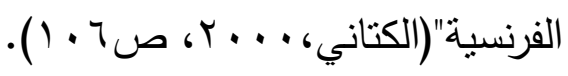

المبحث الثالث: آثار آليات النفوذ الفرنكفوني في العالم العربي: - المي: أولا الأثر على التعليم : يعد التعليم العنصر الأساسي الذي تلجأ إليه

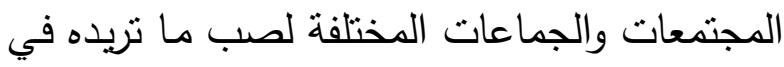
عقول أفرادهـا، وبالتـالي في تشـكيل شخصـياتهم. وبقدر التغيير في عقول الأفراد والثخصيات يكون

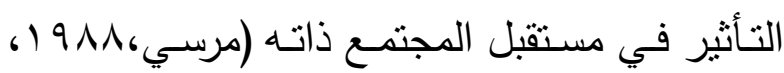
ص ص: ( 


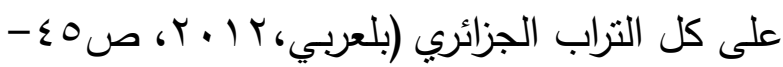
. (Tร

لقد عرفت الفرنكوفونيـة أهميـة التعلـيم ودوره الفاعل في بسط نفوذهـا في الأقطار التي احتلتها

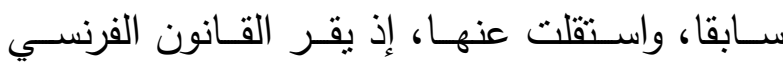

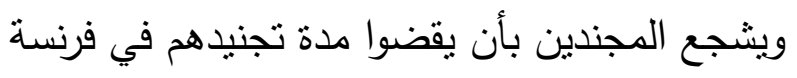

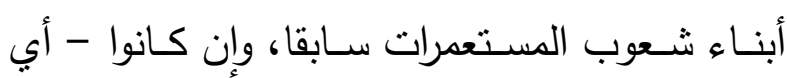
المجندين - ليس لهم أي تكوين تربوي. ومع خطورة

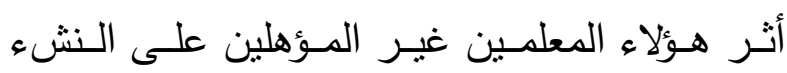

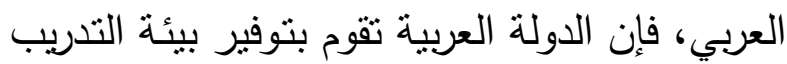

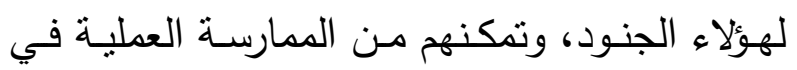

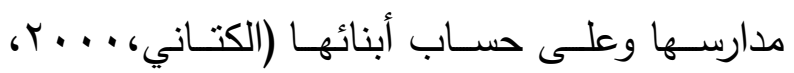

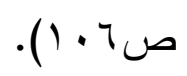

وبـالرغم مـن تغيـر نمـــ السياسـة الفرنسـية

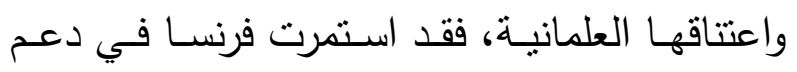

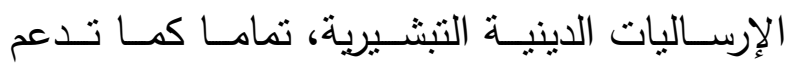
المدارس التابعة للتيار الجمهوري الفرنسي العلماني،

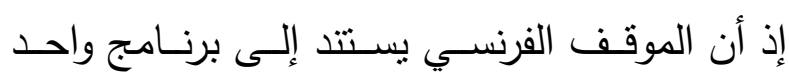
يجري تطبيقه تحت إثـراف حكومي يمتلك ويبرر استخدام الوسائل الضرورية لذلك.

\section{ثنانيا: الأثر على اللفة العربية :}

سباسيا، واجتماعيا واقتصاديا، من خلال الاتفاقيات

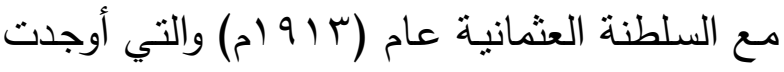
الظروف الملائمة لانطلاقة كبيرة جعلت تعليم اللغة، والتاريخ، والثقافة الفرنسية منتشرةً في جميع أنحاء

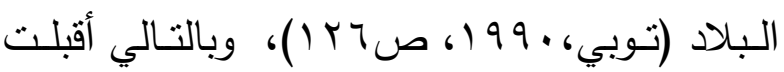

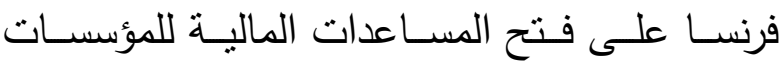
التربوية التي يشرف عليها رجال الدين في الخارج،

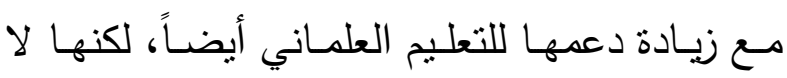
تصرف إلا على المدارس التي تعلم باللغة الفرنسية

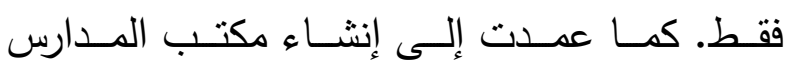
والمؤسسات الفرنسية في الخارج، وارتبط هذا المكتب

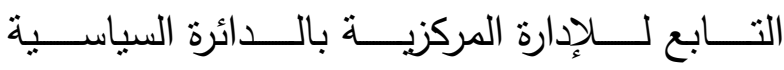

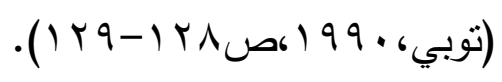

أما في بلاد الثنام، فقد كان للتعليم وجود قوي؛ إذ انتشر فيها على نطاق واسع. وكان متتوعا، لكنه في الوقت نفسه كان فريسة للأطماع الغربية، إذ أن

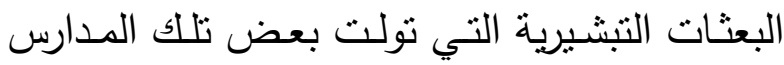

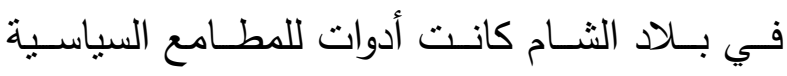
(جحا،911911، ص9019)، وكان لفرنسا نصيب كبير

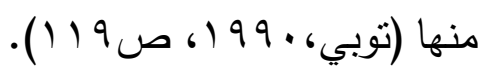
وفي الجزائر، وبعد استقلالها، عمدت فرنسا و في ظل معاهدات الاستقلال للحصول على امتيازات تنص على تكريس تواجدها الثقافي مستقبلا، ومن ذللك: الحفاظ على ملكية (·ـ مركزا بحثيا)، و (1)

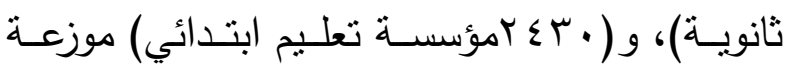


البعثـات الثقافيـة الفرنسـية، والصــحافة الفرنسـية

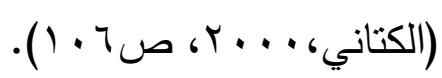

هـذه السياسـة تكـررت في العـالم العربـي، إذ الرابطة الحقيقة بين محو اللغة الوطنية، لغة السكان أصـحاب الأرض العـرب المسـلمين وبـين الفرنسية،

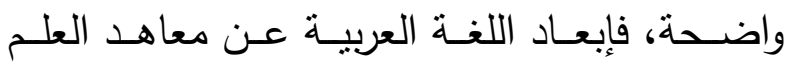
والتعليم خطوة خطيـرة نحو فرنسـة الثـعوب العربيـة

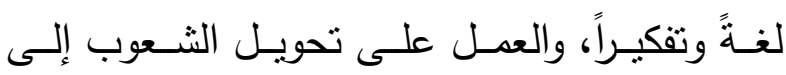

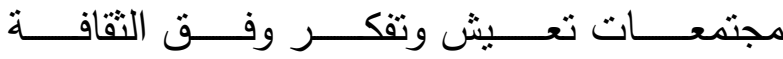

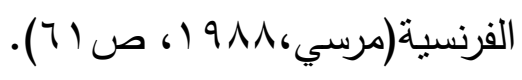

إلا أن السياسـة الفرنكوفونيـة في حربها على

اللغة العربية مختلفة باختلاف الأقطار العربية، ففي الثـام كان ارتكـاز نفـوذ فرنسـا منطلقـا مـن حمايـة الأقليـات النصـرانية الثـامية في الدولـة العثمانيـة بشـكل عـام. لكن سياسـة فرنسـا في محاربـة اللغـة العربية ونشر اللغة الفرنسة في الدولة العثمانية ذات سياســة ازدواجيـة. إذ كانــت الصــحف والـدوريات

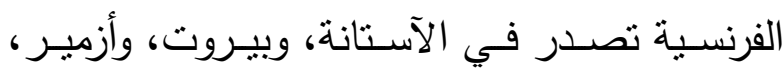
وكان من قراء هذه الصحف أبناء السلطنة العثمانية مع الفرنسيين المنواجدين في السلطنة. ولا يخفى أثر هـذه الصـحف الصـادرة باللغــة و الثقافـة الفرنسـية، ونوعية الكتب التي كانت توزع في أنحاء السلطنة، و الأثر التقـافي لـدور النشـر الفرنسـية المسـماة وتعنـي بيـوت (Masonsde l'union frangaise) الاتحاد الفرنسي، و التي كانت تقيم معارض كتبها
"اللغة هي وعاء الثقافة، وهي وسيلة المجتمع للتعبير عن ذاته، وللمحافظة على تراثه وأصالته، وما مسن أمسة نركت لغتهـا وهجرتهـا إلى غيرهـا إلا ذلـت

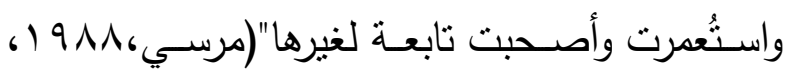

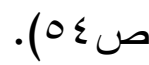

وقـد كـان "مـن شـروط اكتسـاب المعرفـة، و

إيصالها، واستخدامها (المباشر ، و اليومي)؛ أن يتم

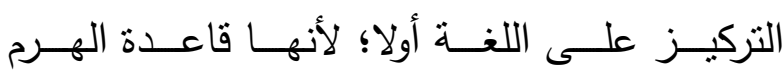
التقافي"(توبي، • 99 (، ص ص 1 (1).

وتتمثل السياسـة الفرنكوفونية في بناء سيادتها في الأقطار والبلدان التي بسطت نفوذها الاحتلالي عليها، وسعت إلى إبقاء شـعوبه تابعة لها في كل جوانــب الحيـاة، فـي اسـتخلال جانــب اللغــة، أي أي توظيف لغـة المستعمر على الأرض "فتعدد اللغات في البلد الواحد يضر أضراراً فادحةً.... والأمسة التي تتعلم كلها بلغـة غير لغتها، لا يمكن أن تقكر إلا بفكر أجنبـي عنهـا... فـإن العلـم إذا أخذتـه بلغتلك

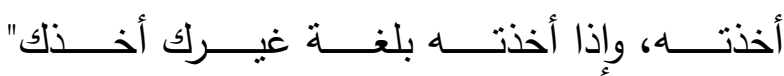

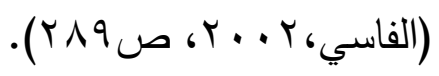

مارسـت الفرنكوفونيـة الاحتلال اللغوي في أوروبـا قديما، وذلك في القرن الثامن عشـر؛ حيث حلـ اللغـة الفرنسـية محل اللغـة اللاتينيـة، وامتـد الاحتلال اللغـوي مـن إيطاليـا جنوبـا إلىى النورفيك والـدنمارك شـمالا، ومـن إنجلتـرا غربـا إلـى بولونيـا

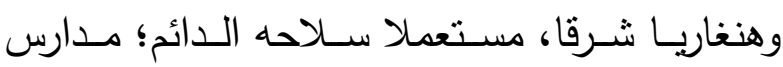


منطلق لحركة التحرر من الحكم العثـاني،إذ أخذ

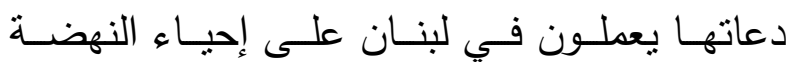
العربية، وذلك من خلال الكتابات والترجمات وإنشاء الصحف والمجلات في الدول العربية (زيادة، IVV ص ب ( ))، هذه النهضة كانت لمواجهة حملة تتريك

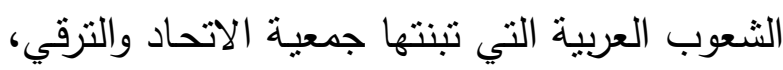
مما أدى إلى مناهضة العرب لهذه السياسة والدعوة

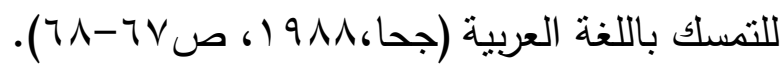
ولأن دعم اللغــة العربيـة في بـلاد الثـام كـان مؤازرًا للمصـالح الفرنسية فقد سـاندت الفرنكوفونيـة اللغة العربية، وأبقت وجود اللغة الفرنسية في الإقليم، خاصــة في لبنـان. إذ كـان المشـروع الفرنسـي في لفي لبنـان يقوم على قاعدة الانخراط التـريجي ضـمن

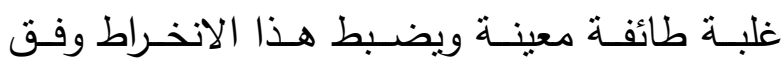
النتظيـر للثنائيــة اللغويــة (العربيــة، والفرنســية)

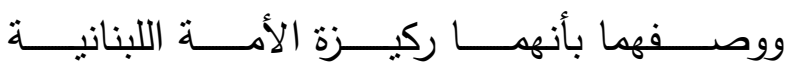

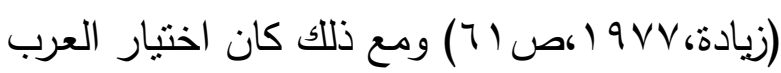
في المشـرق العربـي للغـة الفرنسية اختيـارًا طوعيًا

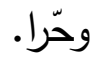

في المقابل كان المنهج السياسي الفرنكفوني مختلفًا تماما في المغرب العربي، إذ كانت الفرنسية

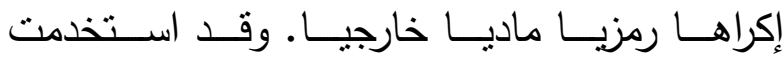

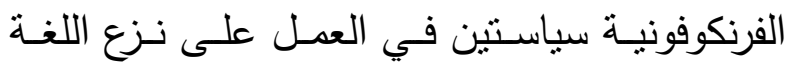
العربية من المغرب العربي، وإحـله اللغة الفرنسية فيه. فمن جانب سعت الفرنكوفونية لفرنسة الثعوب

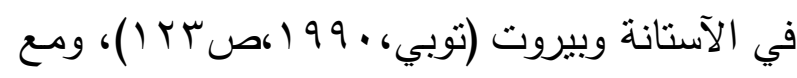

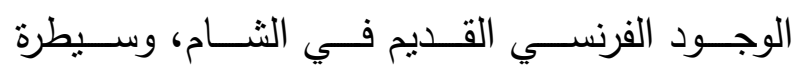
الفرنكوفونية على عدد من دور التعليم؛ بقيت اللغة

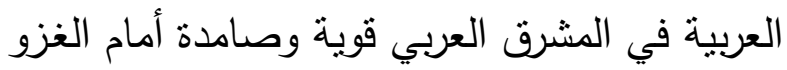
اللغوي وذلك لعدة أسباب منها: أن نصسارى الثـام الذين نزعم فرنسا حمايتهم؛ يقرأون ويتعلمون دينهم بالعربية فقد "رفعت المدارس الطائفية الأجنبية في حلب من شأن اللغة العربية، واهتمت بها أكثر من بن الاهتمام بها في المكاتب الحكومية، وكان النصارى العـرب يعلمــون اللغــة العربيــة فــي مدارســـهم"

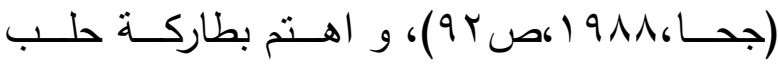
بأدوات الطباعة باللغة العربية، إذ أحضرت الحروف اهن

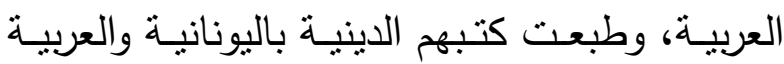

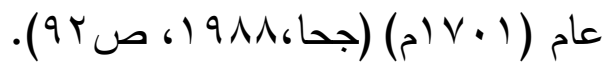

كذلك ما صاحب الحكم المصري ببلاد الثـام

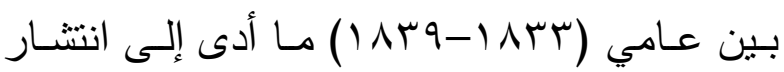

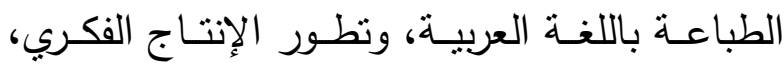

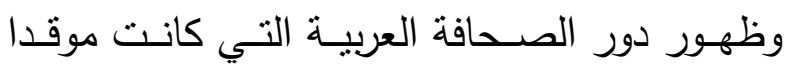
للأفكار القوميـة الوطنيـة بين أبنـاء العرب وخاصـة لونة

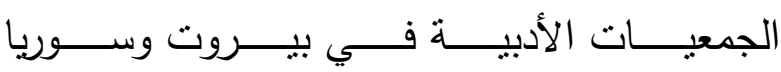

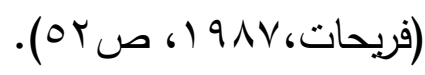

هذا النشاط الفكري في قالبه العربي وجدت فيه

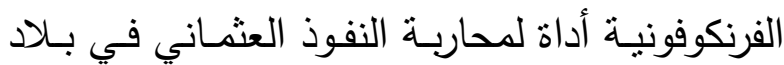
الثـام "فالإرسـاليات الغربيـة ومـا خلفتـه مـن منــاخ ثقافي في الدول العربية وخاصة لبنان نتج عنه أهم 
نعمل على الانتقال مباشرة من البربرية إلى الفرنسية"

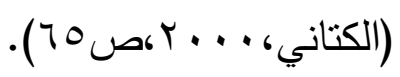

وحتى بعـد الاسـتقلال اسـنطاعت فرنسـا أن

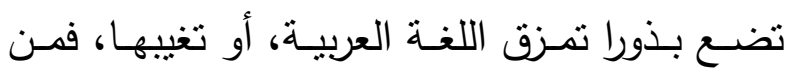
خلال مشروع ميثاق التربية والتكوين في المغرب تم

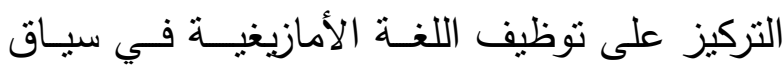
تمزيـــق وحـــــة الثعــــب المغربـــي الدينيــــة

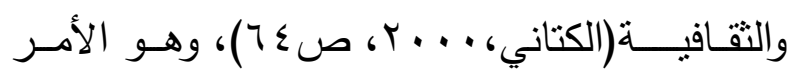
الذي وعاه الثعب الجزائري في سعيه لتحرير أرضه من الاحتلال الفرنسي، فقد طالبت جمعيـة العلماء الجزائـريين باسـترجاع الهويـة الجزائريـة، واسـتعادة

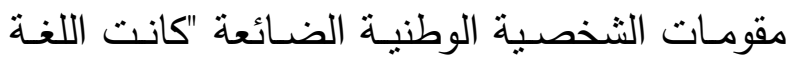
العربية من الأهداف المسطرة في الخطاب الدعوي للجمعية جاعلة منها - أي اللغة - حافزا للحصانة والتحدي ضد سياسة التغريب، والعمل على النهوض هنه

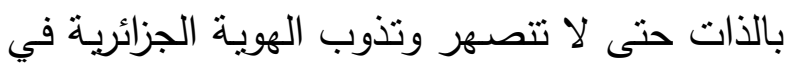

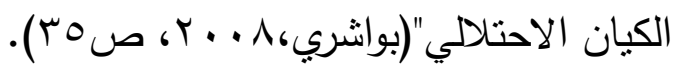

$$
\begin{aligned}
& \text { ثالثا: الأثر على الثقافة: - ماته }
\end{aligned}
$$

الثقافة في معناها العام هي ذللك الإطار الذي

يحوي حياة واحدة، تنتاعم فيها مقتضيات مشتركة،

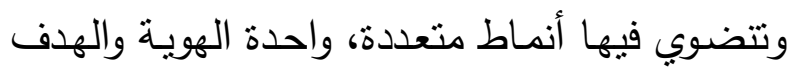
للفرد والمجتمع. فالتقافة هي جماع الهوية والحضارة واللغـة والتـاريخ " ولا يمكن أن نتصـور تاريخـا بـلا

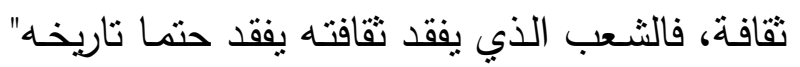

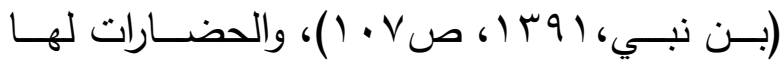

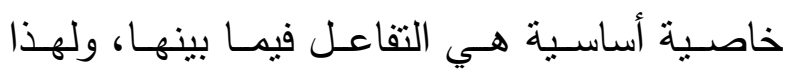

المغربية من خلال وعيها للرابطة الحقيقية بين محو اللغـة العربيـة وبين الفرنسـة، الأمـر الذي لا يحتـاج

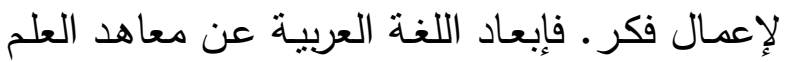
والتعليم، خطوة خطيرة نحو فرنسة الثُعوب المغربية

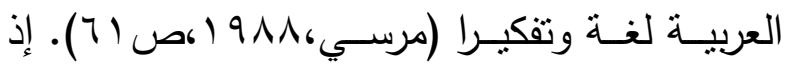

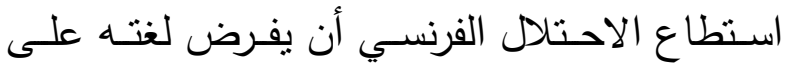

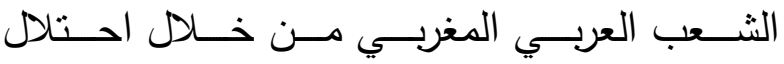
المؤسسات الإدارية، والاقتصادية، وكذلك الثأن في المجال التربوي، إذ بقيت المدارس الابتدائية إلى ما ولى

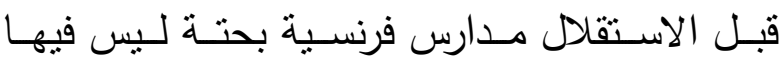

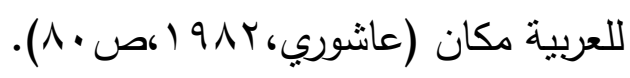

لقد كان إحكام السيطرة على اللغة العربية من الداخل وخاصة التعليم يبرر وضـع منشورات التعليم

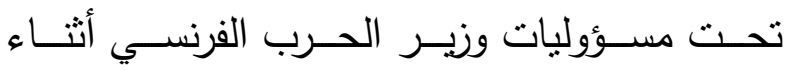
الاحتلال الفرنسي للمغرب العربي (وخاصة الجزائر)

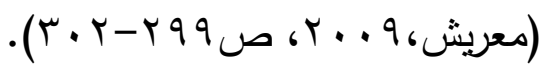
من جانب آخر استخدمت الفرنكفونيـة تعزيز اللهجـات المحلية في مواجهة اللغـة العربيـة؛ لأنها

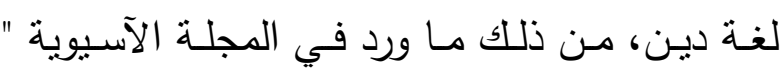

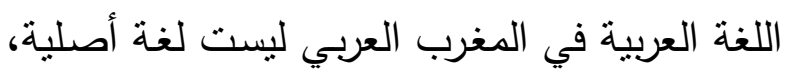

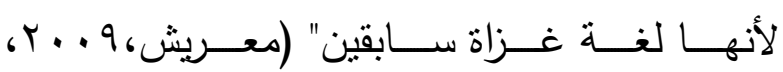

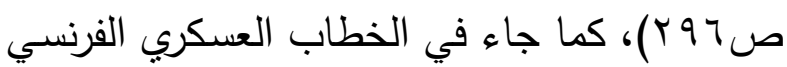
المحتل عام (اب 9 (1)" إن العربية عامل من عوامل نشر الإسـلام، لأن هذه اللغـة ينت تعليمها بواسطة آنس

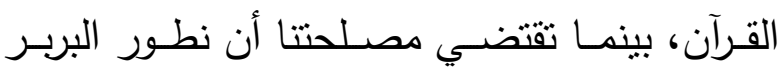
خارج إطار الإنسلام، ومن الناحية اللغوية علينا أن 
فالاتصـال بالحضـارة والنظام الفرنسيين يجعل العربي المسلم يهنم بكل ما هو ضمن إطارهما، لأن

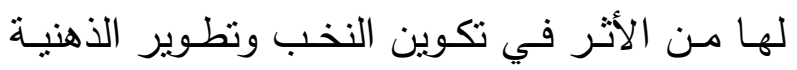
الثيء الكثير ، وهو تطور سلبي يهزم المسلم في هي دينة وحضارته " ففي مؤتمر الطلبة العرب الذي أقيم في هولندا، توصية تنص على عدم ذكر الدين في الدستور القومي وهي توصية أدرجت هناك لإرضاء

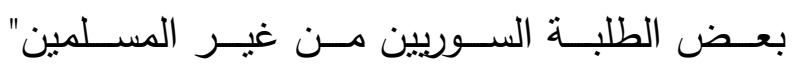

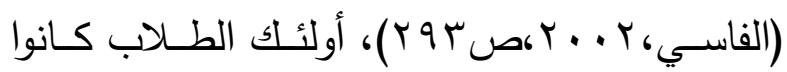
نتاج المدارس الفرنسية في بـلاد الثـام والتي غذيت التي التي

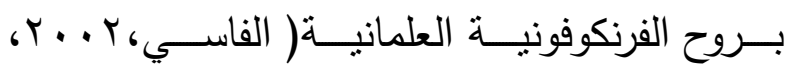

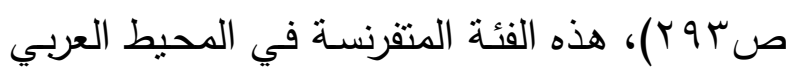

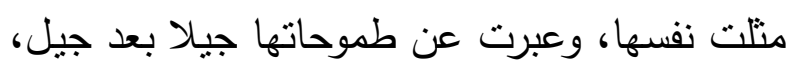

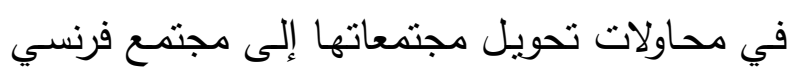

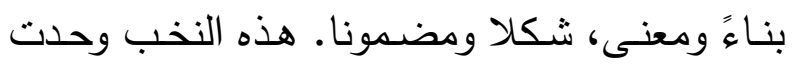

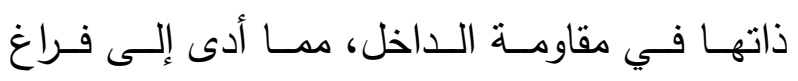
حضـاري، دون أن ينجح في تكوين حضـارة فكريـة وسباسية واجتماعية وأخلاقية تلائم تطوره. وممـا يقال في هذا السياق: إن الفرنسـة قرين

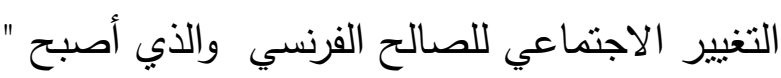
بديلا عن تتصير الأمة إذ يؤدي إلى إبعاد المسلمين

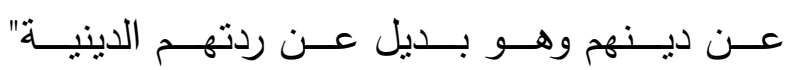

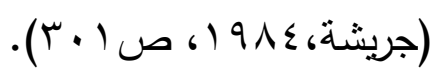
لقد كان الاحتكالك العنيف للمسلم العربي مـع

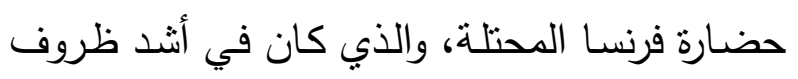

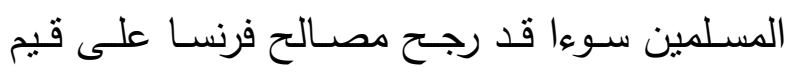

التفاعـل وسـائل متتوعـة منهـا الغـزوات والحـروب

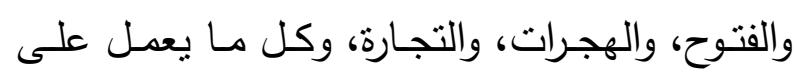
انتقال الأثباء الماديـة والأشخاص والهُ والأفكار والآراء

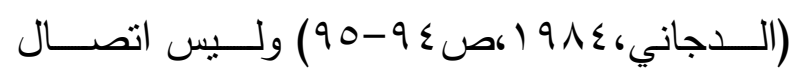
الحضارات بالخطأ، إنما الخطأ ضياع الهوية.

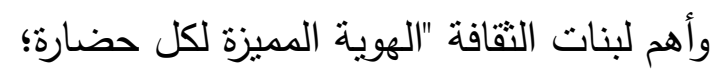
لأنها هي التي نسيطر وتوجد جميع نتائج الحضارة

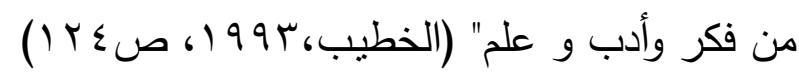

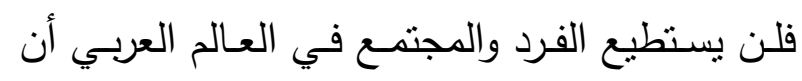

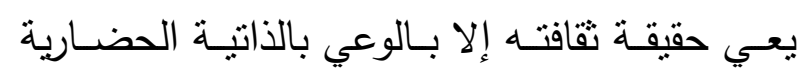

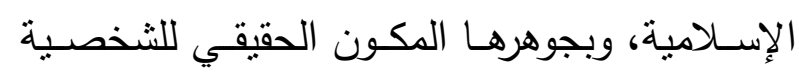
الحضـارية الإســامية والمقـوم الأساســي للكيـان الاجتماعي الإسلامي (مرسي، 911 (، ص الإس).

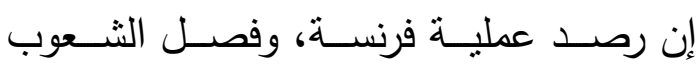
العربيـة عـن دينهـا ولغتهـا وتاريخهـا وحضــارتها صعب، إذ أن عملية الفرنسة وتذويب الهوية العربية

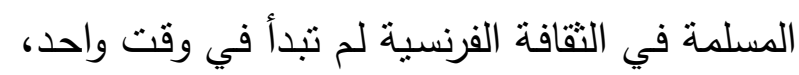
كما أنها من جانب آخر لم تكن قاصرة على مظهر

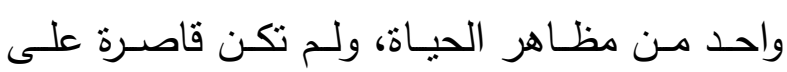

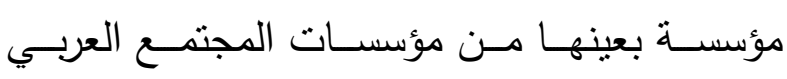

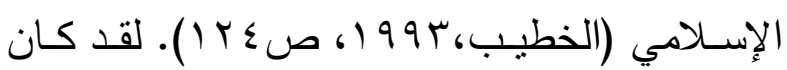

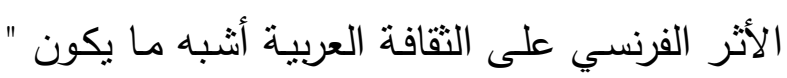

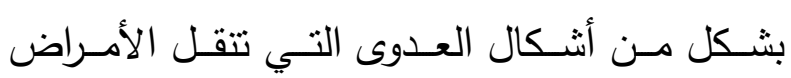
الاجتماعيـة مـن جيل إلى جيل، وهي أفكار لهـدم

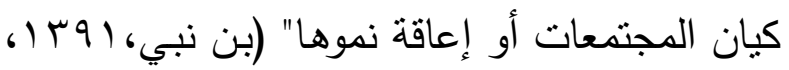

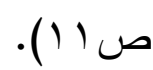


خلق نوع من التوازن في منطقة شمال أفريقيا للحد

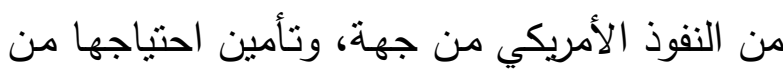

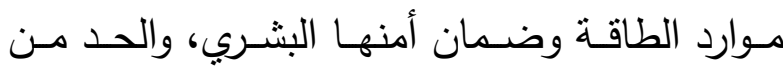
تصــاعد الهجـرة غيـر الثــرعية(بلعربي، Y ا ـr، ص ص (1) r) دخـول اللغـة الفرنسـية فـي صـراع مـع اللغــة الإنجليزية بشكل ملحوظ منذ أكثر من عقدين من

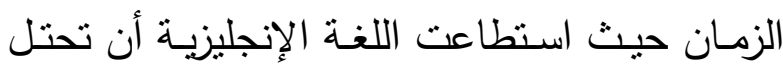

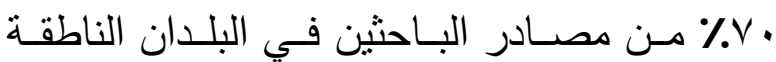

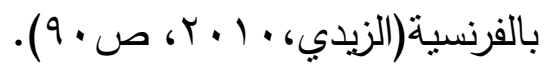
ع) كان نشـاط فرنسـا المحموم في المجال الثقافي في العالم العربي، (من دعم للمؤسسات النقافية في الخـارج، وضــخ الأمسوال الفرنسية إلى اليوم) يؤكد

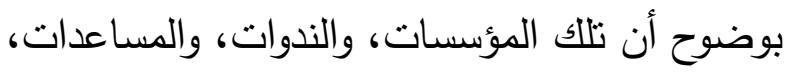
ما كانت إلا ذريعة ووسيلة في الوقت نفسه لإبقاء النفوذ الفرنكفوني في أرض العرب المسلمين. وهي لإني الأرض التـي تحولت إلى سـاحة لصـراع الآخـرين

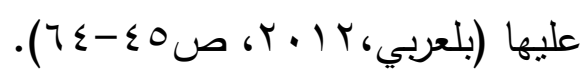

0) تسعى فرنسا في الوقت الحالي لتكوين موضع

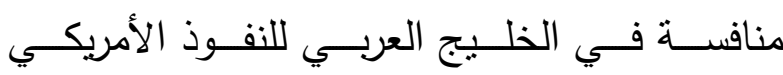
والإنجليـزي (مركـز الإمـارات للاراسـات والبحـوث

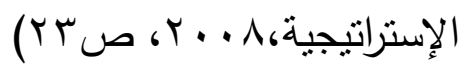

الصــدق والأصــالة، وذلـــك مـن خـــلال نظامهــا الاحتلالـي، وتمثنل عالمهـا الثقـافي فـي وجهـين

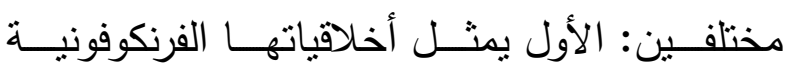

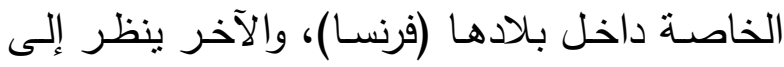

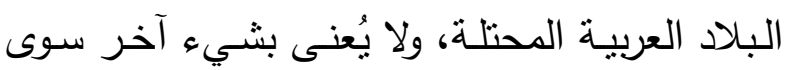

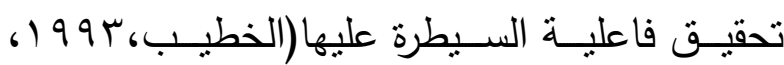
ص إلا أن فرنسا، وفي وقتنـا الحالي أعادت النظر في سياستها تجاه دول العـالم العربي المسلم، تلك اعلك

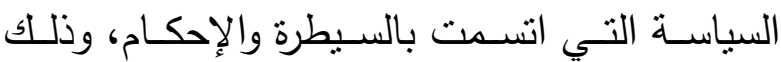
لأسباب: - (ل)

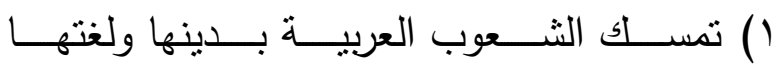

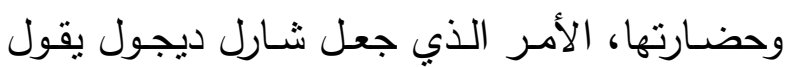
"إنه لمن سخافة الفكر وسخرية الأقدار وانتهاء القيم وسقوط الهمم، أن تعتقد النخبـة السياسية المغربيـة

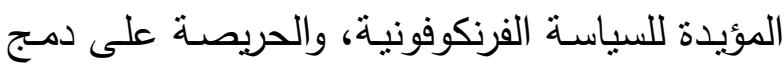
الثـعب المغربي في الحضـارة الفرنسية الغربيـة، أن

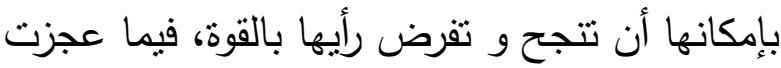
عنه فرنسا رغم قدرتها العسكرية واستعمارها الطويل

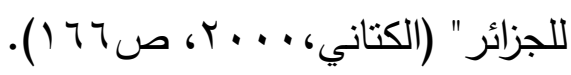
r) وجـود قـوى منافسـة تـزاحم فرنســا في العـالم

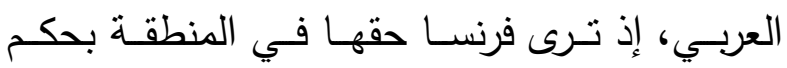
أسبقيتها التاريخية، لذا لا ترغب أن ترى دولة أخرى

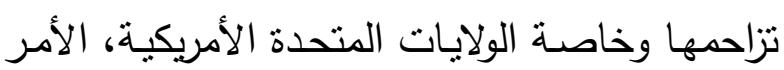

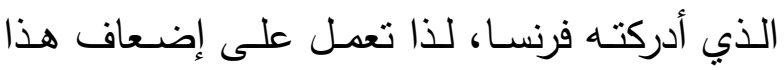

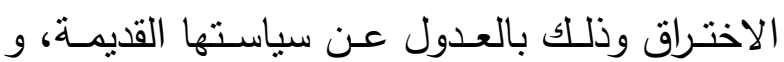




\section{التوصيات}

يخرج هذا البحثث بعدد مـن التوصيات البحثيـة

منها:

- الفرنكوفونية والخليج العربي: تعمل فرنسا لتفعيل وجودها في الخليج العربي حاليا، وإن كان حضورها

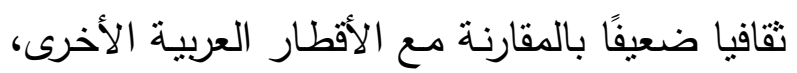
ويمتل هذا الوجود من خلال المؤتمرات والندوات.

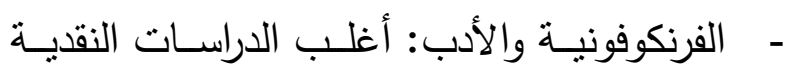
والمتعلقة بالفرنكوفونيـة، هـي دراسـات أدبيـة باللغــة

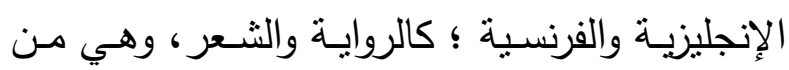
أقوى الطرق لنشر الفرنكوفونية، وهو مجال للبحوث

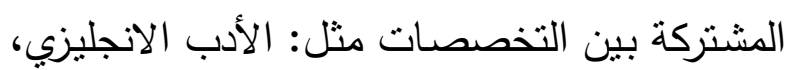

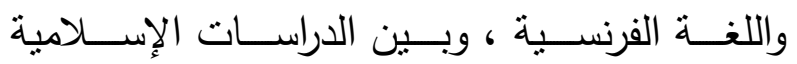
والدارسات السياسية. - الفرنكوفونية والفلسفة: انتشرت الوجودية الفرنسية

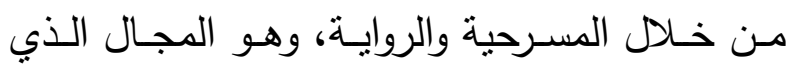
تعمل الفرنكوفونية حاليا لنشره من خلال الفرضيات الفلسفية (ومنها الوجودية والفلسفات الأخرى).
- - مـرت السياسـة الفرنسـية في قالبهـا الفرنكفوني العنصـري، فـي العـالم العربـي بمراحـل متغيـرة، ومتفاوتة خلال قرنين من الزمان. - السياسـة الفرنكوفونيـة في العـالم العربـي، تمثنل فئل جدلية معقدة تسنبطن فكرة واحدة، و تتعدد بوجوه تسفر عن طروحسات سياسية، واجتماعيـة، وثقافيـة ترتبط بعلاقات تأثنير منبادل وفق آليات إنتاجية.

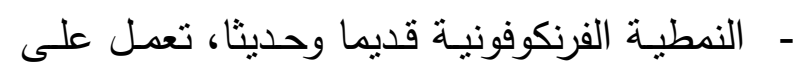

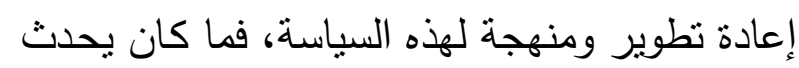

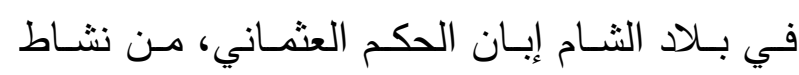
فرنكفوني سياسي ثقافي وتعلمي واجتماعي، يظهر الآن وبقوة في بلاد المغرب العربي.

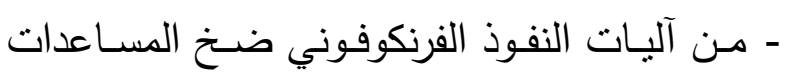
الفرنسية، والتعاون، وإعادة جدولة الديون، وضرورة

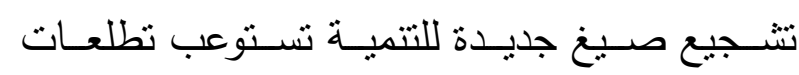

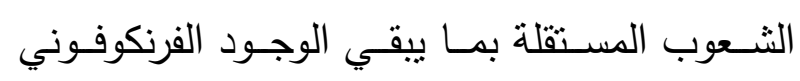
والتبعية له. - تعهل الفرنكوفونيـة على إعـادة تطبيـق سياستها

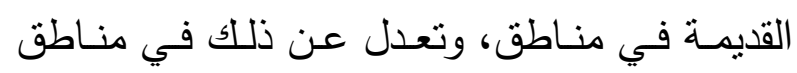

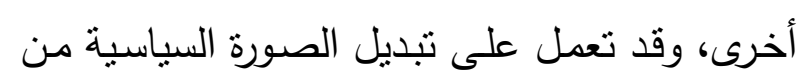

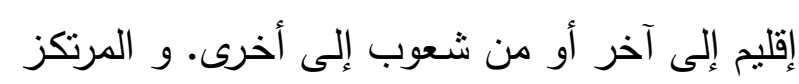
الأساسي لهذه السياسة هو تطوير لحركة الرأسمالية بشكل متعاقب. - مطيــة الفرنكوفونيـة سياسـية منقلبـة، ومتغيـرة حسب موقع فرنسا مع وجود المنافس، (سواء أكان

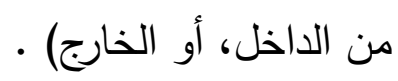




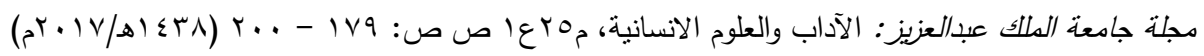

$$
\begin{aligned}
& \text { DOI:10.4197 / Art.25-8 }
\end{aligned}
$$

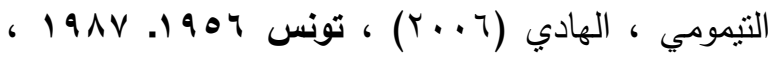

$$
\text { تونس : دار محمد علي للنشر • }
$$

جحا ، فريد (911 (1) ، الحياة الفكرية في حلب (في القرن

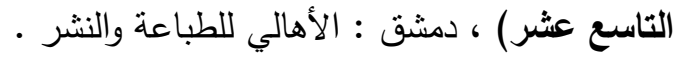

جرشة ، علي (ع/91 ) ، الغزو الفكري والتيارات المعادية للإسلام .علي جريشة. ضمن البحوث المقدمة لمؤتمر

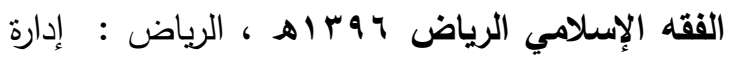
الثقافة والنشر بجامعة الإمام محمد بن سعود الإسلامية.

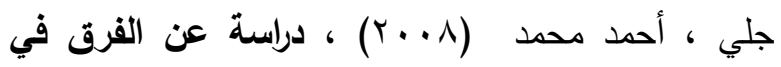
تاريخ المسلمين، الخوارج والثيعة ، الرياض : مركز الملك فيصل للبحوث والدراسات الإسلامية .

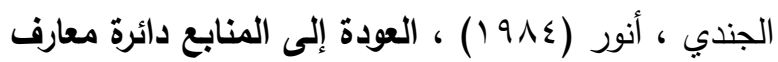
إسلامية. دار الاعتصام.

الخطيب ، سليمان (99 199) ، فلسفة الحضارة عند مالك

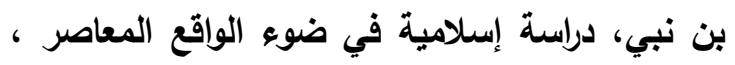

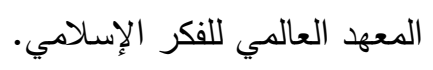
دبوبوا ، جان (991 (1)) ، لاروس معجم فرنسي عربي :

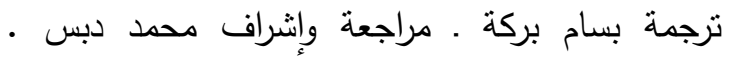

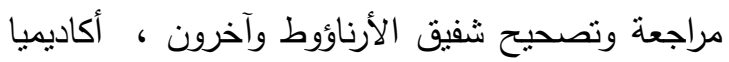
انترناشونال.

الدجاني ، أحمد (ع 9 1، نوفمبر) ، الفكر الغربي والتغيير

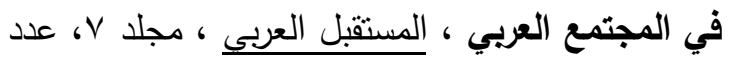

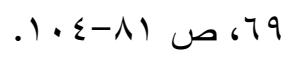

ديورانت ، ول (د.ت) ، قصة الحضارة : ترجمة فؤاد اندراوس ، بيروت : دار الجيل .

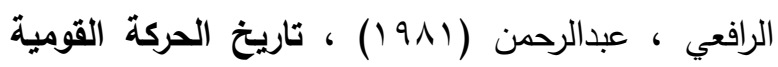
وتطور نظام الحكم في مصر، القاهرة : دار العارف.

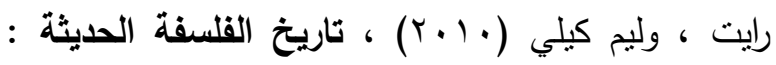
ترجمة محمود سيد ، بيروت : التتوير للطباعة والنشر

$$
\text { والتوزيع. }
$$

\section{القائمة البيبلوغرافية}

إسماعيل، سعاد خليل ( 1919 (1) ، سياسات التعليم في

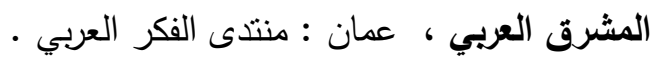

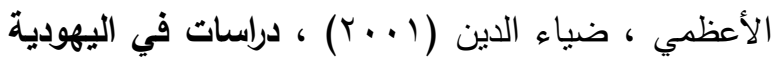

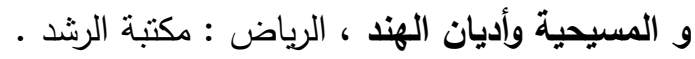

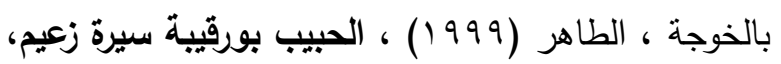

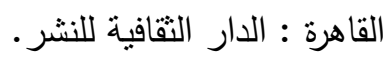
برو، توفيق علي (1991) ، العرب والأتراك في العهد

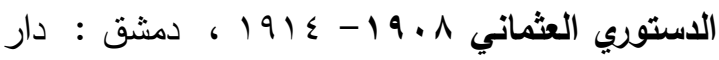

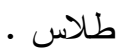
البعلبكي ، منير ( • (199) بيروت : دار العلم للملايين.

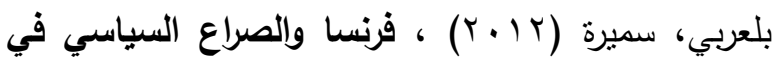
الجزائر ، مجلة الحقوق والعلوم الإنسانية ، جامعة زيان

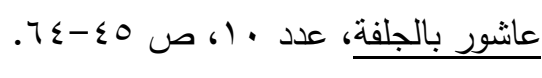

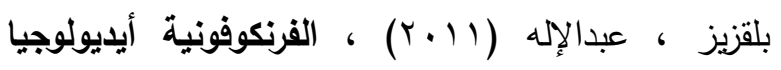
سياسات تحد ثقافي- لغوي ، بيروت : مركز دراسات

$$
\text { الوحدة العربية . }
$$

بن نبي، مالك (| (1) ) ، مشكلة الثقافة ، دار الفكر .

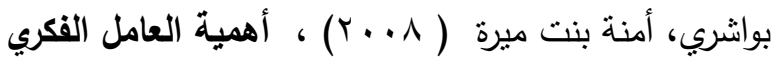
في تثكيل الهوية واسترجاع الحرية الجزائر نموذجا ، الإسكندرية : مؤسسة شباب الجامعة.

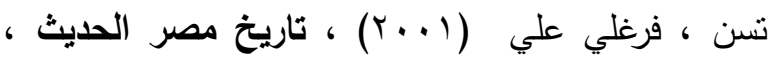

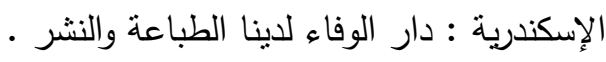
توبي، جاك (9919) ، الإمبريالية الفرنسية والولايات

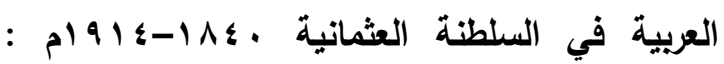
ترجمة فارس غصوب ، بيروت : دار الفارابي • 
عبدالرحمن ، تهاني (11 (Y) نشأة دولة تركيا الحديثة-

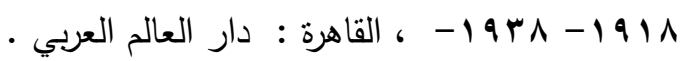

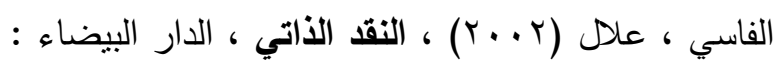
دار الثقافة .

فريحات ، حكمت (9^v ( ) ) ، السياسة (الفرنسية تجاه

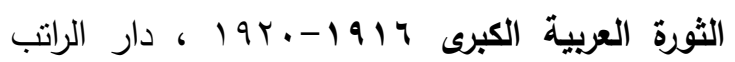

\section{الجامعية.}

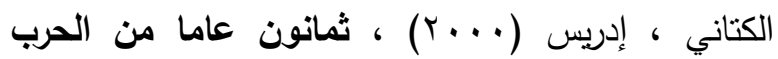

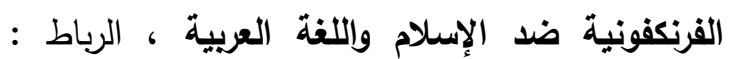

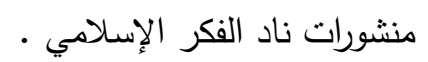

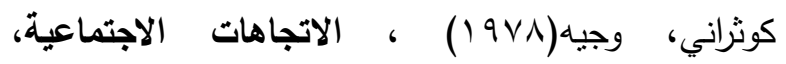

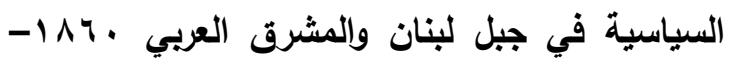

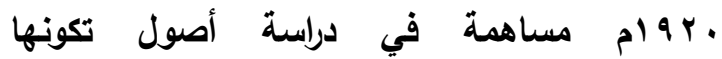

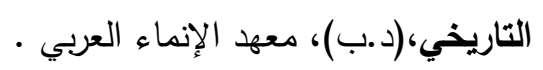

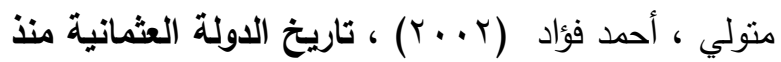
نشأتها حتى نهاية العصر الذهبي ، مصر الجيدة:

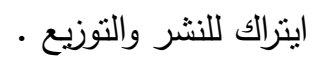
مرسي ، محمد عبدالعليم (9 ( 1) التغريب في التعليم في

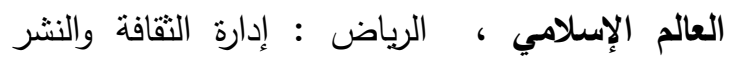

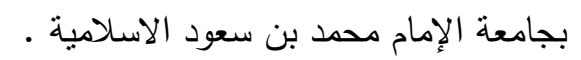

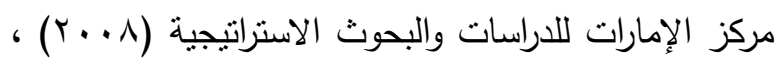
فرنسا والخليج العربي ، أبوظبي : مركز الإمارات

$$
\text { للاراسات والبحوث الاستراتيجية. }
$$

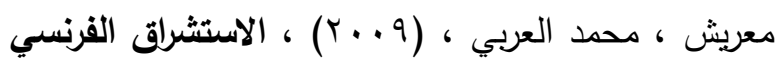
في المغرب والمشرق من خلال المجلة الأسيوية (مAVY-1Arr)

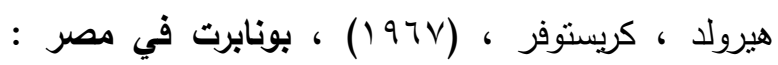

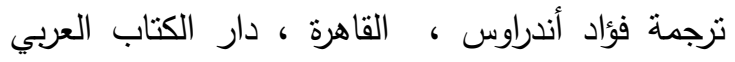

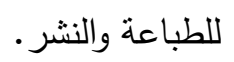

ركيبي ، عبداله (9 . . ب) ، الفرنكوفونية مشرقا ومغريا ، الجزائر : دار الكتاب العربي .

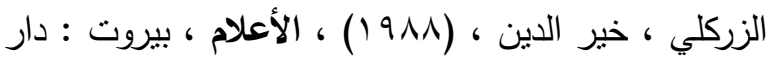
العلم للملايين.

زيادة ، نقولا (د.ت) ، قصة الاستعمار في العالم العربي،

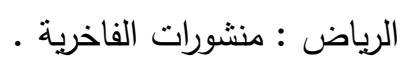
زيادة ، معن (9VV I I) ، لبنان الحضارة الواحدة، بيروت: النادي الثقافي العربي.

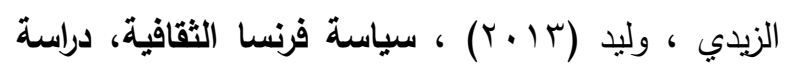

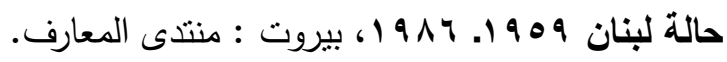

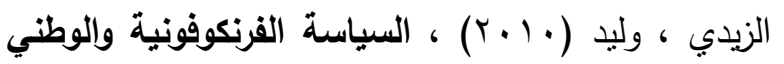

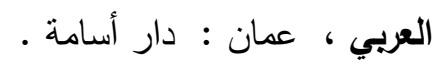

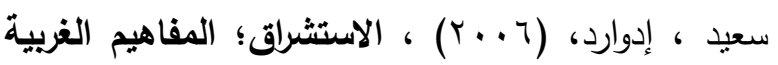

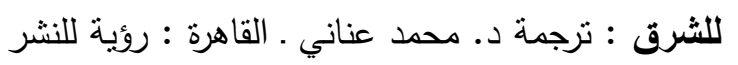
والتوزيع.

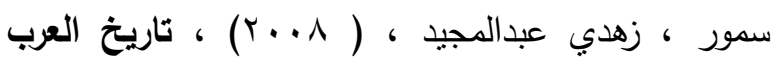
المعاصر ، القاهرة : الثركة العربية المتحدة للتسويق. سولت ، جيرمي ( (1) · ب) ، تفتيت الشرق الأوسط تاريخ الاضطرابات التي يثيرها الغرب في العالم العربي : ترجمة د. نبيل صبحي الطويل ، دمشق : دار النفائس.

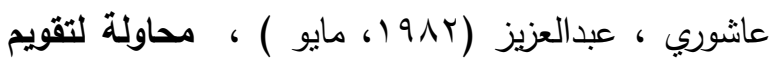

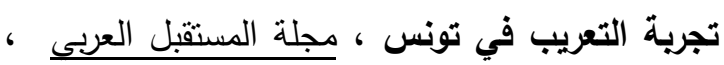

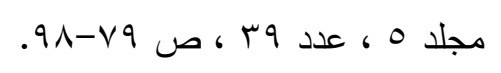

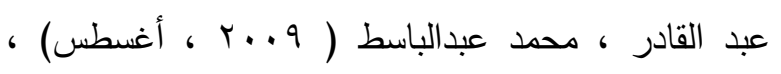

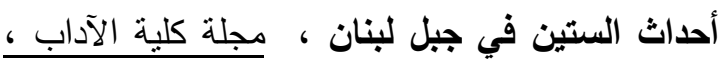

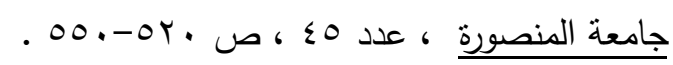

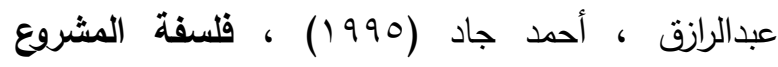

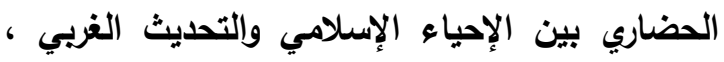
فيرجينيا : المعهد العالمي للفكر الإسلامي. لإسياء الإسي 


\title{
Francophone History and its Effects in the Arabs World
}

\author{
Latifah Al-Ma'yuf \\ King Abdulaziz University
}

\begin{abstract}
Francophone represents one of the methods of alienation and subordination which was carried out in the Arab's world. It has gone through several stages and different styles, which began with the protection of Christians minority in the Levant (in the eighteenth century during the Ottoman rule), then it ended with the colonial military invasion of the Maghreb.

Francophone worked towards the capture of the sources and resources of the Arab nations، and worked towards obliteration of the Arabian Islamic identity. After the liberalization of the Arab countries from military occupation, Francophone continued the abuse of the Arabs. However, the methodology of Francophone was defeated in the Arab's world, but it left behind its existence serious effects, (for instance on the Arabic language, education and culture).
\end{abstract}

Key words: Francophone - Colonialism - Morocco - Arabic language 